\title{
El Dr. Rodolfo Lenz iniciador de la investigación científica de la lengua y cultura mapuches ${ }^{1}$ en Chile
}

\author{
Dr. Rodolfo Lenz, precursor of the scientific investigation \\ of the Mapuche language and culture in Chile
}

Gilberto Sánchez Cabezas²

\begin{abstract}
Resumen
En el presente trabajo se da cuenta de la contribución científica del sabio alemán Dr. Rodolfo Lenz al conocimiento del mapuche (mapudungu(n)), la principal lengua aborigen de Chile, y de la cultura asociada a ella. Su quehacer fue, por consiguiente etnolingüístico, a base de data obtenida de boca de hablantes nativos competentes. Transcurrido más de un siglo su obra continúa vigente, y su conocimiento es obligatorio para quienes se proponen investigar en profundidad sobre la lengua y cultura mapuches.
\end{abstract}

Palabras clave: Rodolfo Lenz. Lengua mapuche (mapudungu(n)). Cultura mapuche. Investigación etnolingüística. Dialectología.

\begin{abstract}
This work provides an account of the scientific contribution by scholar Dr. Rodolfo Lenz to the knowledge of Mapuche (Mapudungun(n)), the main native language of Chile, and the culture associated to it. His endeavor was therefore an ethnolinguistic one, based on information supplied orally by proficient native speakers. Over a century later, his work is still valid, and knowledge of it is mandatory for those who intend to research the Mapuche language and culture in depth.
\end{abstract}

Keywords: Rodolfo Lenz. Mapuche language (mapudungun(n)). Mapuche culture. Ethnolinguistic research. Dialectology.

\footnotetext{
${ }^{1}$ Empleamos la denominación mapuche 'gente de la tierra' (de mapu 'tierra', 'patria' y che 'gente', 'persona'), en vez de araucano (de rag 'greda' y ko 'agua', y la preposición $a$ del español, antepuesta), por ser más universal y representar a toda la etnia. El gentilicio está españolizado y, por consiguiente, puede pluralizarse. El Dr. Lenz empleó ambas denominaciones en sus escritos. En las transcripciones mantenemos el grafemario creado por él y, en las citas en español, la ortografía de la época (por ejemplo $\mathbf{j}$ en vez de g). Empleamos, para las transcripciones, el Alfabeto Mapuche Unificado, uno de los actualmente en uso.

${ }^{2}$ Miembro de número de la Academia Chilena de la Lengua. Miembro correspondiente de la Real Academia Española (RAE). Profesor Emérito (Lingüística) de la Universidad de Chile.
} 


\section{El viaje al extremo del mundo}

¿Cómo se dio que un alemán emprendiera la aventura -sin duda incierta para la época- de viajar al extremo del mundo y llegara a convertirse en el Néstor -así lo han llamado- del estudio e investigación con rigor científico de la lengua y cultura de los mapuches, lo cual nadie hasta entonces había intentado realizar? En verdad, fue un hecho más bien casual. El 29 de abril de 1889 fue fundado el Instituto Pedagógico de la Universidad de Chile, durante el gobierno del Presidente José Manuel Balmaceda (1886-1891), con la finalidad de formar profesores de enseñanza media que el país necesitaba. Al ministro de Educación de la época, Sr. Julio Bañados le fue encomendada la misión de contratar profesores idóneos en Alemania, país cuyas universidades gozaban de gran prestigio académico. La contratación la llevó a cabo el ministro de Chile en Berlín, Domingo Gana. Así llegaron, para impartir las diferentes cátedras de la recién creada institución, los Drs. Juan Enrique Schneider (pedagogía y filosofía), Federico Johow (ciencias naturales), Juan Steffen (historia y geografía), Augusto Tafelmacher (matemáticas), Alfredo Beutell (física y química), Federico Hanssen (gramática histórica) y Rodolfo Lenz (francés, inglés e italiano). Para él -y algún otro compatriota- fue un viaje sin retorno, pues se avecindó con su familia en el país y no regresó a su tierra natal ${ }^{3}$.

${ }^{3}$ El Dr. Rodolfo Lenz nació en Halle an der Saale (Sajonia), Alemania, el 10 de septiembre de 1863. Fueron sus padres Wilhelm Lenz y Marie Danzinger. Tuvo dos hermanos, Walter y Elsa. Inició sus estudios primarios en Bremen, en 1870, para continuarlos, en 1873, en Breslau (Silesia). En 1877 ingresó al Gimnasio "Federico Guillermo" ("Friedrich Wilhelms Gymnasium) de Colonia y, a mediados de 1879, al Liceo Imperial de Metz. Los cambios de colegio se debían a que su padre, empleado de correos, era trasladado con frecuencia. El 1 de agosto de 1882 obtuvo el Certificado de Bachillerato, el cual le permitió ingresar a la Universidad de Bonn, para estudiar lenguas modernas. En el semestre de verano (abriljulio) de 1884 permaneció en la Universidad de Berlín, pero en el otoño del mismo año regresó a Bonn. En esta universidad fue alumno de los catedráticos y profesores encargados de cursos Birlinger, Bischoff, Bucheler, Förster, Franck, Lipps, Menzel, Meyer, Sturzinger, Trautmann, Witte y de los lectores de lenguas extranjeras Piumati y Waridel. En Berlín asistió a las clases de los eminentes profesores Johannes Schmidt y Adolf Tobler (este último era romanista). En agosto de 1886 obtuvo, en Bonn, el grado de Doctor en Filosofía, con la disertación Zur Physiologie und Geschichte der Palatalen (Acerca de la fisiología e historia de las palatales), la cual mereció la máxima calificación (Summa cum Laude). En 1887 comenzó a enseñar en el Friedrich-Wilhelms Gymnasium, de Colonia. Al año siguiente fue nombrado profesor de lenguas en Wolfenbüttel. Ya contratado en Chile, además de enseñar en el Instituto Pedagógico, fue profesor de gramática inglesa en el Instituto Nacional, entre 1895 y 1903. En 1902-1903 se desempeñó como rector interino del Liceo de Aplicación. En 1903 se hizo cargo de la cátedra de gramática castellana. Entretanto, habían aparecido varias publicaciones suyas, tanto en Chile como en el extranjero. En mayo de 1910 participó, representando a la Sociedad de Folklore Chileno (de la cual era presidente), en el XVII Congreso Internacional de Americanistas, en Buenos Aires, con la ponencia Los elementos indios del castellano de Chile. En 1919, al fallecer el Dr. Federico Hanssen, se 


\section{Su interés por investigar el español y el mapuche de Chile}

Cuando llegó a Santiago - un 20 de enero de 1890 - su conocimiento del español era libresco y limitado. Muy pronto le llamó la atención el modo de hablar de los chilenos, sobre todo de los estratos más bajos, y luego pensó que los rasgos peculiares de la pronunciación que presentaba podían deberse a influencia de la lengua mapuche (llamada tradicionalmente araucana). Por ello consideró necesario conocer la lengua indígena. Debido a su acción, se inició en Chile un cambio en el estudio del lenguaje, caracterizado por un rigor científico hasta entonces desconocido. Ello le fue factible debido a la sólida formación, sobre todo en fonética, que había recibido en su Alma Mater de Bonn. Es curioso que fuera un alemán quien viniera a inculcar, en primer lugar a sus alumnos universitarios, el interés por el español popular y por la principal lengua vernácula de Chile. Como esta era propia de 'indios' nadie la valoraba. Su propósito le ocasionó algunas dificultades, las cuales, afortunadamente, no lo hicieron desistir. Al respecto escribió:

En enero de 1891 mandé el primero de mis Chilenische Studien a la revista Phonetische Studien, editada en Marburg por W. Viëtor, porque si lo hubiera publicado en Chile, los "literatos" se habrían reído del gringo loco que tratara los "vicios del lenguaje de la plebe ignorante" como materia de trabajos científicos (Lenz 1924: 10).

Pero no se desanimó y continuó sistemáticamente sus estudios dialectológicos. Aunque se había formado con maestros 'neogramáticos' (Junggrammatiker), para los cuales el estudio del lenguaje solo podía ser desde una perspectiva histórica, su objeto de investigación fue el actual, vivo y espontáneo ${ }^{4}$. A propósito, escribió Claudio Vicuña:

[...] enseñó durante 40 años a mirar en la lengua un fenómeno independiente de la teoría de los gramáticos, a observarla en su realidad íntima, en su fonética espontánea, que va degradándose de boca en boca a través de las generaciones, en la mutación inverosímil de sus significados, en sus analogías arbitrarias, en el ilogismo creciente o decreciente de su sintaxis verdadera (Vicuña 1938: 9).

hizo cargo de la cátedra de gramática histórica castellana. En 1921 viajó a Europa, donde, además de visitar a parientes (a su anciana madre y sus dos hermanos), pronunció varias conferencias (en Alemania y en España). Durante la travesía en barco, desde Curazao, aprovechó de estudiar la lengua criolla local, el papiamento (con la ayuda del hablante nativo Natividad Sillie). En 1922 asumió la dirección del Instituto Pedagógico, pero por poco tiempo (renunció al año siguiente). En 1925 se acogió a jubilación. En 1931 fue recibido como Miembro Académico de la Facultad de Filosofía y Ciencias de la Educación de la Universidad de Chile. Falleció en Santiago el 8 de septiembre de 1938, tres días antes de cumplir 75 años. (para mayores detalles, véase Escudero 1963).

4 "Es preciso que el lingüista conozca la lengua en su uso vivo y natural..." (Lenz 1914, Prefacio Comentarios del pueblo araucano a II: 242). 
Importante en su investigación del lenguaje fue la influencia del lingüista alemán Georg von der Gabelentz ${ }^{5}$. Según este, la investigación debe comenzar por el examen del 'habla' (die Rede, la parole saussureana), realizándose una recolección metódica (ein zweckbewusstes Sammeln) de muestras orales de lenguaje. Consideraba, además, imprescindible el conocimiento de lenguas habladas en otros continentes, entre ellas las de América, cuyas estructuras son muy diferentes de las que poseen las lenguas indoeuropeas. En estas se había basado, hasta entonces, la lingüística comparada. También, según von der Gabelentz, "la investigación lingüística histórica encontrará en suelo americano algunas de sus minas más ricas, estando la mayoría de ellas recién perforada(s) ${ }^{6}$ ". El Dr. Lenz estuvo plenamente de acuerdo. En más de un pasaje de su obra destaca los méritos de von der Gabelentz, cuya metodología le parecía espléndida (1895-1897, Introducción: X; 1893, 1900, 1901). La labor llevada a cabo por el Dr. Lenz fue enorme. En el poco tiempo libre que le dejaban sus clases en el Instituto Pedagógico (de inglés, de francés, de gramática española) examinó de manera exhaustiva y crítica -"con espíritu de sabio y paciencia de benedictino", según Vicuña- un gran número de fuentes escritas (crónicas coloniales, historias, gramáticas antiguas y recientes, tanto de lenguas indígenas como del español, léxicos diversos, obras literarias, etc.) que contuvieran información sobre sus temas de investigación, en especial sobre el mapuche. Recolectó lengua oral, tanto española como mapuche, las cuales registró con exactitud, debido a su experticia fonética. Se preocupó también del folklore nacional, llegando a ser, además de fundador y presidente de la Sociedad de Folklore Chileno (entre 1909 y 1915) 7 .

El Dr. Lenz ha influido de manera profunda y permanente en muchos estudiosos e investigadores chilenos -y también extranjeros-, tanto en el ámbito de la dialectología del español de Chile como de la lengua y cultura mapuches, desde comienzos del siglo XX. Cabe mencionar, por ejemplo, a los misioneros capuchinos alemanes en la Araucanía, Fray Félix José de Augusta y Ernesto Wilhelm de Moesbach, los cuales han manifestado que la lectura de los Estudios

\footnotetext{
${ }^{5}$ Georg von der Gabelentz (1840-1893). Lingüista y sinólogo alemán. Fue precursor de F. De Saussure. Profesor en Leipzig y Berlín. Su importante obra Die Sprachwissenschaft, ihre Methoden und bisherigen Ergebnisse, publicada por primera vez en 1891, tuvo poca difusión. Reeditada en 1901, 1969 y 1972. Véase el estudio introductorio de E. Coseriu "Georg von der Gabelentz und die synchronische Sprachwissenschaft".

6 "Auf amerikanischem Boden wird die sprachgeschichtliche Forschung einige ihrer ergiebigsten Minen finden, und die meisten sind eben erst angebohrt" (von der Gabelentz 1972:258).

${ }^{7}$ Fue, además, la persona encargada de los programas de enseñanza del castellano y lenguas extranjeras (inglés y francés) en los liceos de Chile. Publicó varios textos como autor o coautor. ¡Pasó, pues, siempre muy ocupado!
} 
Araucanos los motivaron para recolectar textos en mapuche ${ }^{8}$. Al respecto, el Dr. Lenz revisó y preparó para su publicación el extenso manuscrito de la obra Vida y costumbres de los indígenas araucanos en la segunda mitad el siglo $X I X$, la cual contiene, en su mayor parte, los relatos que el cacique Pascual Coña comunicó al misionero Ernesto Wilhem de Moesbach. Ambos religiosos adoptaron su sistema de transcripción fonética, con leves modificaciones 9 .

También el investigador de la cultura mapuche Tomás Guevara recopiló textos antropológicos en mapuche, los cuales forman parte de sus obras Folclore araucano y Las últimas familias y costumbres araucanas (Santiago, 1911 y 1913). Aunque no lo declara, se reconoce el empleo del sistema de transcripción fonética del Dr. Lenz (con sustitución parcial o total de un par de grafías), como también la modalidad de traducir literalmente algunos materiales (por ejemplo, los refranes).

También el joven profesor mapuche de enseñanza básica Manuel Manquilef (que ejercía en el Liceo de Temuco y era colaborador de Guevara en sus trabajos de campo), publicó, estimulado por el Dr. Lenz, sus Comentarios del pueblo araucano (I. La faz social y II. La jimnasia nacional (juegos, ejercicios guerreros $i$ deportivos $i$ bailes)). Ambos trabajos aparecieron en los Anales de la Universidad de Chile, correspondientes a los años 1911 y 1914. El Dr. Lenz atribuyó mucha importancia al hecho de que un mapuche describiera la etnología y folclore de su pueblo. Por primera vez un indígena había escrito en su propia lengua ${ }^{10}$.

A su vez, Sperata Rovillo de Saunière publicó sus Cuentos populares araucanos y chilenos (Santiago, 1915) a instancias del Dr. Lenz (y del señor Ramón A. Laval, estudioso destacado del folklore chileno), algunos de los cuales él revisó personalmente.

Cabe mencionar también -en esta breve reseña- al distinguido estudioso de los cuentos folklóricos de Chile, Dr. Yolando Pino Saavedra. Aunque no llegó a ser un "araucanista" profesional, se consideró un discípulo del Dr. Lenz (lo

\footnotetext{
8 "La idea de consultar a textos araucanos nos ha sido inspirada por la lectura de los citados "Estudios Araucanos" del Dr. Lenz" (De Augusta 1910, Prólogo: VII).

9 "Los tipos que nos han servido para representar ciertos sonidos propios de la lengua mapuche, son casi los mismos de que hace uso en sus "Estudios Araucanos" el renombrado lingüista y Profesor de Estado Dr. Dn. Rodolfo Lenz, con quien nos consultamos antes de decidirnos a adoptar los caracteres..." (De Augusta 1903, Prefacio: VII). "La fonética empleada es la misma que estableció el Dr. Rodolfo Lenz, el padre de los araucanistas modernos, que también aplicó el P. Félix José de Augusta" (Wilhelm de Moesbach 1930:10). 10 "Es la primera vez que un descendiente inmediato de la heroica raza cantada por Ercilla, un joven que en su infancia no ha hablado otra lengua que el mapuche, publica una obra científica [...]" "¿Qué fuente más intachable podemos desear para conocer la etnolojía i el folklore mapuche que las descripciones dadas por un hijo de la misma nación?" (Manuel Manquilef1911, Prefacio del Dr. Lenz: 393- 394).
} 
llamó "mi venerado maestro"). Además de adaptar cuentos contenidos en los Estudios Araucanos, a fin de hacerlos más comprensibles para el público en general, recopiló en español, entre 1952 y 1970, un total de 36 nuevos relatos. Los obtuvo en varios lugares de la Araucanía, sobre todo en la zona del lago Ranco (XIV Región de los Ríos) (Pino Saavedra 1987: Prefacio e Introducción).

Entre los estudiosos no chilenos figura el sabio alemán Dr. Robert LehmannNitsche, residente durante muchos años en Argentina, quien recopiló y publicó cuentos mapuches. Una parte de los mismos, como también otros materiales (incluida una versión de los diálogos del Dr. Lenz en lo que él denominó dialecto waidüfche) forman parte de su Nachlass (legado), el cual se conserva en el Ibero-amerikanisches Institut, Preussischer Kulturbesitz de Berlín, Alemania ${ }^{11}$.

Muchos otros investigadores de la lengua y cultura mapuches han seguido, hasta el presente, el camino trazado por el Dr. Lenz. Podrán considerarse mayormente sus discípulos quienes representen virtudes del Maestro, como su rigor científico, su modestia de verdadero sabio y su profundo sentido humano, mostrado hacia los mapuches, cuya lengua y cultura se propuso investigar.

\section{Estudio e investigación de la lengua mapuche}

\subsection{Viajes a la Araucanía y recolección de materiales}

A fines de 1891 realizó su primer viaje a la llamada Araucanía, a Collipulli ${ }^{12}$, a fin de recolectar materiales que representaran el estado actual de la lengua. En esa ocasión solo obtuvo 14 frases, pero ningún texto narrativo. Después de haber estudiado la pronunciación de varios indígenas y comprobado la influencia fonética del mapuche en el español -según creyó- pudo haber abandonado el estudio de la lengua vernácula,

Pero lo poco que había aprendido de esta lengua me pareció tan interesante i los datos de las gramáticas antiguas tan insuficientes, que resolví dedicar una parte del tiempo que me dejaban mis ocupaciones oficiales como profesor de idiomas del Instituto Pedagójico de Chile, al estudio del idioma indíjena [...]"(Lenz 1895-1897, Introducción: IV).

$\mathrm{Su}$ objetivo principal fue recoger materiales auténticos, fidedignos del lenguaje de los indígenas actuales. En febrero de 1894 viajó nuevamente a Collipulli, donde logró obtener del cacique Juan Amasa la traducción de 400 frases, la descripción de una trilla a la manera indígena y trozos de poesía, en dialecto picunche ${ }^{13}$. En el invierno de ese mismo año estudió el dialecto huilliche, en Santiago, con Domingo Quintuprai, a quien tuvo de huésped en

\footnotetext{
${ }^{11}$ Han sido publicados recientemente.

${ }^{12}$ Collipulli es actualmente comuna y ciudad de la provincia de Malleco, IX Región de La Araucanía, Chile.

${ }^{13}$ Sobre los dialectos, véase 4.2.
} 
su hogar. En dos meses de trabajo obtuvo también la traducción de 400 frases y varios textos, de los cuales el Viaje al país de los manzaneros es considerado como el primer documento en dicho dialecto. Los otros tratan de la erupción del volcán Calbuco (en la provincia de Llanquihue, IX Región de los Lagos, Chile), de un episodio histórico que narra la participación de un abuelo en la batalla de Maipú (que selló la independencia de Chile, el 5 de abril de 1818), de la llegada de un forastero a una ruka [casa] mapuche (con el consiguiente pentukun, o salutación) y de un canto de borracho.

Un hecho inesperado, fortuito, resultó ser en definitiva determinante para su estudio del mapuche. Víctor Manuel Chiappa, dueño del fundo Santa Rosa, ubicado cerca de la actual ciudad de Victoria (IX Región, cerca de Temuco) le escribió, en abril de 1895, solicitándole instrucciones para llevar a cabo sus estudios particulares sobre el mapuche. Al mismo tiempo le remitió varios textos (3 cuentos, 3 naciones históricas y 9 poesías), los cuales le habían sido dictados por su empleado Calvun ${ }^{14}$ (Segundo Jara). Este hecho fue para el Dr. Lenz providencial, un verdadero golpe de suerte, pues el inteligente indígena, de quien provenían los textos, era una fuente inagotable de lenguaje. Los textos proporcionados por Calvun constituyen la mayor parte de los Estudios Araucanos (Estudios V al XI). En febrero de 1896 viajó nuevamente donde su amigo y colaborador, permaneciendo en el terreno tres semanas. El hacendado Chiappa ya había recolectado algunos textos dictados por Calvun. Durante su permanencia corrigió textos que le habían sido enviados previamente a Santiago por su amigo (en 1895). Según consigna, en el terreno mismo apuntó 14 textos en prosa, una poesía y la traducción de las frases que ya había publicado en el dialecto picunche. Por último, en 1897 permaneció 10 días en Cholchol ${ }^{15}$, como huésped del misionero anglicano Carlos Sadleir. Realizó excursiones diarias a las reducciones (comunidades) vecinas, particularmente a las de los caciques (longko) Domingo Coñuepán y Ramón Painemal. Su viaje no fue muy productivo, pues los indígenas, por ser verano, estaban ocupados en sus cosechas $\mathrm{y}$, por consiguiente, poco dispuestos a ser entrevistados. Además, no encontró informantes aptos. Solo uno -llamado Juan Kallvün (no era pariente de Segundo Jara)- pudo serle de alguna utilidad. Antes de regresar a Santiago dio instrucciones al misionero Sadleir "para que pueda en adelante continuar sus estudios lingüísticos i etnolójicos en conformidad con mis propios proyectos" (Lenz 1895-97: 313). El misionero anglicano obtuvo de Juan Kallvün la traducción de 345 frases en dialecto moluche, las cuales constituyen el Estudio XII de los Estudios Araucanos. El Dr. Lenz -hasta donde estamos informadosno regresó a la Araucanía.

\footnotetext{
${ }^{14}$ Más exactamente Kallvün.

${ }^{15}$ Cholchol es actualmente comuna y pueblo de la provincia de Cautín, IX Región de La Araucanía, Chile.
} 
Las permanencias del Dr. Lenz donde los mapuches fueron breves, pero nadie antes lo había hecho, con el propósito de estudiar científicamente la lengua aborigen. Por consiguiente, fue un pionero en el trabajo lingüístico de campo. Además, entonces no era fácil como en el presente desplazarse desde Santiago hasta la Araucanía. No tuvo la ventaja de los misioneros capuchinos de su tiempo que residían permanentemente en los lugares, junto a los indígenas.

\subsection{Los Estudios Araucanos}

\subsubsection{Importancia de la obra}

Es la obra más importante, de carácter etnolingüístico, pues no solo da cuenta del estado de las principales variedades dialectales del mapuche (huilliche, picunche, pehuenche y moluche), sino también de diferentes aspectos de la cultura vernácula. Aparecieron publicados primero en los Anales de la Universidad de Chile, por entregas, entre los años 1895-1897 y, luego, en un volumen aparte de 485 páginas. Son 12 en total y constituyen un corpus amplio y variado, único en ese momento, que permitió conocer el estado de la lengua mapuche a fines del siglo XIX, como también aspectos inéditos de la cultura de sus hablantes. Hasta entonces no se poseía ninguna muestra de la lengua recogida con una metodología lingüística rigurosa. Desconfiando de la autenticidad de los textos doctrinarios (oraciones, pláticas, confesionarios) contenidos en las gramáticas coloniales, compuestos por los mismos misioneros, se propuso obtenerlos en el terreno. Es cierto también que con el propósito de comprobar la influencia del mapuche en el español de Chile ${ }^{16}$. Por otra parte, los cronistas coloniales no se interesaron por registrar la lengua y en sus obras solo suelen figurar antropónimos y topónimos, generalmente mal transcritos; ocasionalmente se registra alguna frase (por ejemplo, en el Cautiverio Feliz, de Francisco Núñez de Pineda y Bascuñán, hay un pequeño fragmento del Padre Nuestro y cuatro versos $)^{17}$. Los Estudios Araucanos han motivado a estudiosos posteriores de la lengua y cultura mapuches, y su autor ha sido considerado como el "padre de los araucanistas".

\footnotetext{
${ }^{16}$ Sostuvo que el español de Chile era español con sonidos araucanos. Esta tesis indigenista fue refutada definitivamente por Amado Alonso. Véase "La interpretación araucana de Lenz para la pronunciación chilena" (Alonso, Amado y Raimundo Lida: 281-289). Alonso reconoció - eso sí- la importancia del Dr. Lenz como fonetista y la contribución que hizo a la disciplina.

${ }^{17}$ En la obra Chilidúǵú del misionero jesuita alemán Bernardo Havestadt se encuentran 28 versos de una canción de machi (curandero/a) y una minifábula.
} 


\subsubsection{Breve reseña de los Estudios Araucanos}

La obra contiene los siguientes materiales en mapuche, con traducción al español:

Viaje al país de los manzaneros, narrado en dialecto huilliche por el indígena Domingo Quintuprai. En el texto -de 28 páginas- se describe un viaje que realizó Quintuprai a la Argentina, con la finalidad de vender chicha aguardiente. El mismo Dr. Lenz lo consideró importante, por las siguientes razones:

- Es el primer documento de cierta extensión publicado en dialecto huilliche.

- Es el primer documento publicado de acuerdo con los progresos de la Lingüística, hasta ese momento, transcrito fonéticamente de manera minuciosa y sin cambios en el estilo y la sintaxis "tal como salió de la boca de mi profesor" (1895-1897, Estudio I: 4).

- El texto contiene muestras de todos los estilos: narración lírica, diálogos ordinarios y ceremoniosos (estilo de koyagtun), descripciones y discursos en estilo elevado, invocaciones religiosas y hasta delirios de hombres ebrios.

- La narración abunda en pasajes interesantes y característicos para el conocimiento de las costumbres, de la vida privada, política y religiosa de los indígenas.

\section{Diálogos en cuatro dialectos}

- 371 diálogos en dialecto huilliche (en Estudio II), dictados por el indígena Domingo Quintuprai.

- 280 diálogos en dialecto picunche (en Estudio III), 266 dictados por el cacique Juan Amasa y 14 por una indígena del lugar.

- 345 diálogos en dialecto pehuenche (en Estudio V), proporcionados por Segundo Jara (Calvun).

- 345 en dialecto moluche (en Estudio XII), dictados por Juan Kallvün.

El Dr. Lenz tomó como modelo los diálogos contenidos en la obra de Ernst Middendorf Die aymara Sprache, publicada en Leipzig, en 1881. Los Diálogoscomo también otros textos de los Estudios Araucanos- incluyen muchas notas explicativas.

Tanto el Viaje al país de los manzaneros como los Diálogos son los documentos más extensos en dialecto huilliche que existen. En la actualidad el dialecto se encuentra muy deteriorado ${ }^{18}$.

\footnotetext{
${ }^{18}$ Nosotros realizamos un trabajo de campo en la zona huilliche y no encontramos hablantes competentes que pudieran dar respuestas al cuestionario aplicado por el Dr. Lenz, ni proporcionar textos de alguna extensión. Por ello, el material obtenido por él tiene gran valor histórico.
} 
Trozos menores en picunche y en huilliche

Son los siguientes: 1. la fiesta de la trilla entre los indigenas de Collipulli, narrada por Juan Amasa; 2. un episodio histórico, narrado por Domingo Quintuprai en dialecto huilliche; 3. la erupción del volcán Calbuco, descrita también por Domingo Quintuprai y 4. la llegada del forastero, también narrada por el mismo indígena; 5. canto de borracho, narrado también por el mismo. Son textos comparativamente breves.

Cuentos en pehuenche chileno (Estudios V - IX), narrados por Segundo Jara (Calvun).

Se distinguen los siguientes tipos:

- 12 cuentos de animales. En varios de ellos interactúa el zorro -considerado en la cultura mapuche como el prototipo de la astucia, de la pillería e, incluso, de la maldad- con otros animales (El zorro y el tigre, El zorro y el zorzal, etc.).

- 7 cuentos míticos (por ejemplo, La novia del muerto y El viejo Latrapai).

- 5 cuentos de origen europeo (por ejemplo, Las tres hermanas y Los tres hermanos).

- 7 cuentos históricos, lo cuales se refieren a personajes importantes mapuches (por ejemplo, el cacique Kalvukura). Se incluyen también tres cantos.

\section{Cantos}

Se incluyen:

- 4 cantos en dialecto moluche.

- 18 cantos en dialecto pehuenche, de diverso tipo (poéticos, guerreros, épicos, y otros que denominó 'sueltos').

Trozos descriptivos y documentos para el folklore araucano

- Son siete textos.

Los Estudios Araucanos comprenden, además de los diálogos en cuatro dialectos, 77 textos, unos breves; otros, extensos. Se trata de un corpus amplio y variado, quizá todavía no superado.

\subsubsection{Algunas limitaciones de los materiales}

No obstante sus innegables méritos, los Estudios Araucanos adolecen de algunas limitaciones, de las cuales estaba plenamente consciente su autor, "puesto que mis propios conocimientos han ido creciendo a medida que aumentaba el trabajo" (Lenz, 1895-1897: 449). Dada su modestia, exhortó a los interesados en el tema a comprobar o rectificar sus estudios. Le urgía publicarlos "puesto que no puedo saber si jamás llevaré a cabo la vasta tarea 
que me he impuesto, como ha sucedido tantas veces cuando una desgracia o una casualidad ha impedido a autores de poner el punto final a obras de largo aliento, quisiera que no quedaran perdidos para siempre mis trabajos inconclusos [...]" (Lenz 1895-1897, Introducción: IX-X). En efecto, la tarea que se impuso fue enorme y, por ello, no la pudo en definitiva cumplir como anhelaba. Tocante a su conocimiento práctico del idioma vernáculo escribió:

Con el ejercicio repetido i algunos años de trabajo he llegado a comprender más o menos perfectamente cualquier testo apuntado en araucano; pero, como nunca he tenido, durante unas semanas siquiera, la posibilidad de practicar el idioma con indios, alcanzo difícilmente aún hoy, a entender una conversación rápida. Podría espresar ideas sencillas de un modo intelijible para un indio, así como un estudiante según el antiguo método gramatical alcanza a hacer una traducción al latín o al francés, no exenta de incorrecciones. Aun el más profundo análisis filolójico de un idioma no da la facilidad de hablarlo siquiera medianamente (Lenz 1919: 36).

Una parte del corpus no es del todo idiomática, sobre todo los diálogos en los diferentes dialectos. Resulta evidente que, en más de una vez, su informante indígena no comprendió cabalmente las preguntas que le fueron formuladas en español y, por ello, las respuestas no correspondieron exactamente a tales preguntas, o contenían omisiones. A propósito, relata su experiencia con el cacique picunche Juan Amasa:

Vi luego que era inútil preguntar al indio por el sentido especial de un par de sílabas. El solo era capaz de repetir el sentido del conjunto, aunque hablaba bastante bien el castellano [...] Este sistema de partir de un testo castellano i pedir la traducción era naturalmente peligroso, porque, a veces, el indio entendía mal. Si yo le dirijía, por ejemplo, una pregunta en castellano, en vez de traducirla al mapuche, como yo lo deseaba, contestaba él a la pregunta en su lengua (Lenz 1919: 35).

Ello pudo deberse a condiciones poco favorables para realizar el trabajo de campo, para el cual dispuso de muy poco tiempo. Por lo mismo, no pudo volver a controlar las respuestas con el informante, con la calma necesaria. Quizá también influyó la gran cantidad de preguntas que contenía el cuestionario de E. Middendorf. Si hubiera podido aplicarlo sin prisa el resultado habría sido seguramente otro. También los textos de relatos no son siempre coherentes, contienen errores gramaticales y la traducción no es, en varios pasajes, exacta. Por otra parte, solo dispuso de un informante para obtener las muestras de cada dialecto (Domingo Quintuprai, Juan Amasa y Segundo Jara), y de un colaborador permanente, el hacendado Víctor Chiappa, el cual, aunque recibió instrucciones del Dr. Lenz, no poseía formación lingüística, especialmente en fonética, para recopilar los textos. Lo primero tendrá una consecuencia importante que 
precisaremos más adelante; respecto de lo segundo, algunas de las expresiones contenidas en los textos anotados por Chiappa resultaron ser ininteligibles.

\subsubsection{El pehuenche chileno de los Estudios Araucanos}

Como ya señalamos, todos los materiales en pehuenche chileno de los Estudios Araucanos fueron entregados por Calvun, el cual no era un verdadero pehuenche sino un moluche. Sin embargo, según el Dr. Lenz (Calvun)

ha vivido desde unos años atrás casi siempre entre los pehuenches que en gran parte han venido a esas rejiones de la falda chilena de la cordillera entre los cursos superiores de los ríos Malleco i Cautín, después de las guerras de esterminio llevadas a cabo en la Arjentina hace unos quince años" [es decir, alrededor de 1880] (Lenz 1897: 10).

Por no ser su informante un verdadero pehuenche reconoce que vaciló mucho en la denominación del dialecto, pero

como Calvun me dijo que ya no se distinguía en el habla de sus amigos pehuenches entre los cuales vivía, i como yo mismo tampoco he notado diferencias entre él i los demás indios de la comarca, me parece conveniente denominar este grupo "pehuenche chileno" (Lenz 1895-1897: 134).

Posteriormente, al examinar los diálogos recolectados por el misionero Sadleir, en dialecto moluche, reconoció que este se distinguía poco del lenguaje de Calvun, siendo las diferencias de construcción y vocabulario insignificantes (Lenz, 1895-1897: 448).

La convivencia prolongada de Calvun con los pehuenches pudo ser la causa de las frecuentes fluctuaciones de $/ \mathbf{f} / \mathrm{y} / \mathbf{v} /$ que ocurren en los textos (véase Suárez, 1959).

A fin de ilustrar más sobre este punto, y poder comparar, consignamos algunas frases recopiladas por el Dr. Lenz, y la versión correspondiente en pehuenche chileno actual (hablado en el Alto Bío-Bío, VIII Región de Chile), obtenidas por nosotros.

Muestra del pehuenche recopilado por el Dr. Lenz (A) y pehuenche actual (hablado en el Alto Bío-Bío, VIII Región, B).

\section{Diálogos}

1. Llaman afuera. Ve a ver quien es.

A Mütrümüi wekun. Amune inei chei. ${ }^{19}$

B Ngütrümüy ché wekún. Amungé, kintúlmengé ñi ánchi ${ }^{20}$.

\footnotetext{
${ }^{19}$ Mantenemos la transcripción del Dr. Lenz.(Véase Estudios Araucanos: 138-139).

${ }^{20}$ Transcribimos empleando el Alfabeto Mapuche Unificado.
} 
2. Un caballero quiere verte.

A Kiñe kawaKero kəpa-peeimu.

B Kíñe wentrú küpápenéymu.

3. Pregúntale quien es, qué necesita.

A Ramtufine inei chi, chem duamnien

B Ramtuvé ñi ngén, chém ñi duamngén.

4. ¡Que entre!

A ¡Konpape!

B ¡Konpápe!

5. Dile que iré en seguida.

A Fei pifine: feyi-kachi amoan.

B Eypivé: veykáchi amón.

6. Buenos días amigo, ¿qué necesitas?
A Mari mari wenüi; chem duamimi?
B Márimári wenû́y, ¿chém duámngimí?

7. Vine a verte, a hablar contigo.
A Kəpan pepapeyu, dunulpapetuyu.
B Pepápeyu, dungúlpapéyu.

8. Me alegro mucho de verte; ¡siéntate!
A Fentepun ayüeyu tami peviel; anün,e!
B Mütté trepélkawün támi pevélmù, anüngé!

9. ¿Dónde estabas, niño? No salí, estuve aquí nomás.

A Cheu məlepeimi pəchi kampu? T'ipapelan; təva $\mathrm{mt} \cdot \mathrm{n}$ məlepen.

$\mathrm{B} \quad$ ¿Chéw mülépimí püchí kámpu? Tripápelán, tüvámù mülepén.

10. Estoy muy cansado.

A Mətte kansalen; t'anakunuan.

B Mütté atrulén, tranákünowtón.

11. ¿Qué se siembra en ese campo?

A Chem am tukuñekei təveichi mapu meu?

$\mathrm{B} \quad$ ¿Chém tukúngekí véychi mápu mù?

12. Aquí hay papas dulces, papas fritas, buen pan de maíz.
A Təfa məlei kochi poñi, yaņa $\Lambda$, kəme kofke wa
B Tüva mù mülí kóchi poñú, avǘn poñú ka kümé medkǘn wá.

En el pehuenche actual se registra, comparado con el recolectado por el Dr. Lenz, la ocurrencia regular de /v/ (que suele realizarse como [ $\beta]$ ) y la monoptongación de /ei/ en /i/. Las frases muestran también las pocas diferencias en la estructura gramatical y léxica de las variedades dialectales, lo cual contribuye a hacerlas mutuamente inteligibles. 


\section{Aportes al conocimiento de la lengua mapuche}

En diferentes publicaciones, a partir de los Estudios Araucanos, el Dr. Lenz trató aspectos estructurales del mapuche; sin embargo, no dejó una descripción cabal de la lengua vernácula. Su proyecto era publicar una gramática completa del mapuche, tanto desde una perspectiva sincrónica como diacrónica, con análisis de la fonética, la morfología, la sintaxis e, incluso, la estilística, siguiendo la metodología propuesta por von der Gabelentz. Dada la dimensión que tendría la obra escribió: "[...] temo solamente que no alcancen mis fuerzas para una tarea de tanta magnitud como sería una gramática crítica completa" (Lenz 1895-1897: Introducción: X-XI). Desgraciadamente, no pudo llevar a cabo su proyecto. En los últimos años de su vida mantenía todavía la esperanza de materializarlo. En el prólogo de Vida y costumbres de los indígenas araucanos en la segunda mitad del siglo XIX, de Ernesto Wilhelm de Moesbach, escribió al respecto:

[...] yo aprovecho esta ocasión para volver a estudiar con estos inmensos materiales nuevos la lengua mapuche y me halago con la esperanza de que talvez, si alcanzan mis fuerzas, así puedo preparar un estudio gramatical abstracto, puramente filosófico, que tuve la intención de escribir desde 35 años. [...] En mi libro La oración y sus partes ( $2^{\mathrm{a}}$. Edición, Madrid, 1925) he dado algunas indicaciones sobre el análisis científico del mapuche, que debe prescindir de todas las clasificaciones gramaticales del latín. En mapuche no existe ni siquiera la división gramatical en substantivos, adjetivos y verbos. Todos los conceptos de substancia, cualidad y fenómeno, sufren las mismas alteraciones morfológicas. Creo, por esto, que un análisis abstracto de una lengua americana tan particular será de valor para la lingüística científica (apud Wilhem de Moesbach 1930: 6-7).

\subsection{Relación del mapuche con otras lenguas de América y tipología}

Postuló que el mapuche no tiene relación de parentesco con otras lenguas de América:

Lo que sí parece fuera de duda es que el araucano no tiene ninguna relación directa de parentesco ni con los quechuas i aimaraes, ni con los guaraníes, lules o abipones, ni con los huarpes, tehuelches, ni con las tribus fueguinas, es decir con ninguno de sus vecinos. Se distingue de todos ellos tanto por las raíces de las palabras, como por toda la construcción gramatical [...]” (Lenz 1895-1897, Introducción: XXII).

Tipológicamente es una lengua aglutinante incorporativa [incorporante], como muchas otras de América, aunque presenta diferencias, por ejemplo, respecto del quechua. En una lengua como el mapuche la forma verbal es la proposición propiamente tal "el centro lógico que espresa la relación que hai entre las otras palabras" (Barros Arana-Lenz: 45). Posteriormente han sido propuestas vinculaciones del mapuche con otras lenguas de América. 


\subsection{Dialectos del mapuche}

Propuso la existencia de cuatro dialectos (tres al comienzo de sus investigaciones y posteriormente un cuarto, cuando dispuso de mayor información).

La gran lei fonética que distingue los dialectos araucanos se debe a la tendencia de cambiar $\mathbf{v}, \mathbf{d}, \mathbf{z h}, \mathbf{z}, \mathbf{l}, \boldsymbol{\kappa}$, en $\mathbf{f}, \mathbf{z}, \mathbf{s h}, \mathbf{s}^{\mathbf{s}}, \mathbf{l}, \mathbf{\kappa}$ ', es decir, de suprimir el sonido de la voz en todos los sonidos fricativos.-- "Esta tendencia -sostuvo- ha atacado la $\mathbf{v}$ en todos los dialectos actuales, pero en la frontera norte está todavía la $\mathbf{v}$ al lado de la $\mathbf{f} \mathbf{y}$ se pronuncia sin diferencia təva o tofa [este, esta, esto]. En pehuenche es regular $\mathbf{f}, \mathbf{z}, \mathbf{s h} ; \mathbf{z}$ ' esta al lado de s'; entre los huilliches todos los sonidos son casi siempre sin voz, solo la l' y la $\boldsymbol{K}$ ' ocurren a menudo con voz" (Lenz 1895-1897, Introducción: XXIII-XXIV).

4.2.1. Picuntu o picunche [de pikum, pikun 'norte' y che 'gente'], hablado entre los ríos Bío-Bío y Valdivia. Según el Dr. Lenz, el dialecto conservaba con mayor fidelidad el estado fonético del idioma mapuche. Su pronunciación coincidía con la transcrita, en sus gramáticas, por los misioneros jesuitas Andrés Febrés y Bernardo Havestadt, la cual se caracterizaba por conservar, en general, las consonantes fricativas /v/ y / / / (véase Estudio III).

4.2.2. Huilliche [de willi 'sur' y che], hablado al sur del río Valdivia. Era el dialecto más diferenciado, no solo en el léxico y en "algunas sílabas preformativas", sino que en él se ha producido un ensordecimiento de las consonantes fricativas arriba señaladas (véanse Estudios I y II).

4.2.3. Pehuenche [de pewen 'el pino araucaria' (Araucaria araucana) y che], "la lengua de la jente de los piñones en la falda oriental de la cordillera, desde donde en tiempos pasados han vagado por la pampa argentina hasta las cercanías de Buenos Aires" (1895-1897, Introducción: XXII-XXIII). También en este dialecto se habría producido el ensordecimiento ya mencionado ${ }^{21}$.

4.2.4. Moluche (de ngulu, mulu 'occidente'). En una etapa posterior de su investigación dialectológica postuló la existencia de un dialecto moluche, hablado en la zona de Cholchol (Araucanía central). Es -afirma- el más arcaico (por ejemplo, conserva la v sonora), pero no se diferenciaba fundamentalmente,

\footnotetext{
${ }^{21}$ Según el Dr. Lenz, en el pehuenche es regular f, z, sh; z' está al lado de s' (Lenz 18951897, Introducción: XXIII). En el pehuenche hablado actualmente en el Alto Bío-Bío ello no se cumple; solo ocurren regularmente $/ \mathbf{v} / \mathrm{y} / ð /$. No se registra $/ \check{\mathrm{s}} /$. En el pehuenche del sector sur (zona de Panguipulli, actual XIV Región de los Ríos) ocurre regularmente /f/, como muestran los textos recopilados por el misionero capuchino Fray Sigifredo von Frauenhäusl, coautor de las Lecturas Araucanas, publicadas por su cofrade Fray Félix José de Augusta (1910, 1934).
} 
por una parte, del pehuenche de su informante Calvún y, por otra, del picunche ${ }^{22}$.

$\mathrm{Su}$ deseo era estudiar el mapuche hablado en Cholchol, Nueva Imperial, Pitrufquén, Villarrica, Lebu y, además de este, en otros puntos de la costa chilena, pero no pudo realizar un proyecto tan ambicioso. Para ello habrían sido necesarias muchas permanencias in situ. ¡En verdad, una tarea enorme para ser llevada a cabo por una sola persona!

La labor en este aspecto del Dr. Lenz representa un primer intento por dar cuenta científicamente de la dialectología mapuche, y sus resultados tuvieron el carácter de provisorios. A pesar de algunos estudios realizados posteriormente por otros investigadores, todavía no se dispone de un estudio acabado de los dialectos del mapuche.

\subsection{Fonética y grafemario del mapuche}

El Dr. Lenz dedicó especial atención a la descripción fonética del mapuche, dada su excelente preparación en la disciplina. Su principal maestro de fonética había sido en Bonn el profesor Moritz Trautmann ${ }^{23}$. La descripción de las articulaciones es exacta, minuciosa, realizada de acuerdo con los progresos alcanzados por la disciplina a fines del siglo XIX. Al parecer, intuyó la noción de fonema, pues señala que algunos sonidos tenían "valor distintivo", es decir, implicaban un cambio de significado (por ejemplo las consonantes ápicointerdentales o posdentales $[\mathbf{t} \cdot],[\mathbf{l} \cdot]$ y $[\mathbf{n} \cdot])$, mientras otros eran "sin valor distintivo" (las consonantes ápico-supraalveolares, o prepalatales [n'] y [l']) (Lenz 1895-1897: 130, 135). Sin embargo, no consignó pares mínimos que demostraran su aseveración. Posteriormente precisó más la idea:

Escribir un idioma quiere decir representar cada sonido "distintivo" por un signo especial. Distintivos son en cada lengua aquellos sonidos cuya sustitución por otro podría variar el significado; matices distintos de sonidos que no pueden producir tal efecto, sino que dependen en su uso de ciertas leyes fonéticas especiales de cada lengua, no necesitan escribirse con signos diferentes en una escritura fonética práctica; solo en trabajos científicos que quieren estudiar tales leyes fonéticas que el pueblo aplica inconscientemente, se exige una traducción fonética rigurosa que distingue por signos particulares todos los matices que el oído del observador atento alcanza a notar" (Lenz 1920: 32).

\footnotetext{
22 “[...] Pero en ningún caso es probable que el pehuenche sea esencialmente distinto del moluche, así como tampoco el picunche se aparta mucho de los otros dos dialectos. Las diferencias sintácticas que también parecen insignificantes, solo se podrán establecer después de una comparación detallada de las diferentes versiones" (Lenz 1895-1897: Estudio XII, 448).

${ }^{23}$ Importante fonetista alemán de la época, autor de Die Sprachlaute im allgemeinen und die Laute des Englischen, Französischen und Deutschen im besondern. Leipzig: Verlag von Gustav Fock, 1884-1886.
} 
Es decir, un alfabeto o grafemario debe representar -en términos actualessolamente los fonemas; no los alófonos. Por ello, empleó para representar los sonidos "distintivos" (fonemas) del mapuche un alfabeto (o grafemario) a base del alfabeto español y de algunos símbolos tomados de los sistemas de transcripción fonética que conocía (el Lepsius, el Maître Phonétique). Su sistema de transcripción le permitió describir, por primera vez y con gran exactitud, los aspectos fonofonológicos del idioma vernáculo. En justicia cabe denominarlo Alfabeto o Grafemario Lenz.

\subsection{Estructura gramatical}

Según el Dr. Lenz, el análisis lingüístico de la lengua vernácula debe prescindir de todas las clasificaciones gramaticales basadas en el latín, pues

en mapuche no existe ni siquiera la división gramatical en sustantivos, adjetivos y verbos. Todos los conceptos de substancia, cualidad y fenómeno sufren las mismas alteraciones morfológicas. Creo, por esto, que un análisis abstracto de una lengua americana tan particular será de valor para la lingüística científica" (Lenz 1930: 7).

Desechó también la Gramática General -basada en la lógica de Aristóteles-

puesto que no hai una manera absoluta de pensar, sino que cada lengua tiene su manera particular de unir las ideas. Si este hecho indudable no se les ocurre todos los días a todos los filólogos, es porque les falta generalmente la posibilidad de comparar [...]. Nada de lo que nosotros creemos tan natural en nuestras lenguas es indispensable; ni la declinación, ni la conjugación, ni el activo, ni el pasivo, ni toda la división de las palabras en diferentes partes de la oración. El hombre puede pensar sin distinguir las categorías de verbo, adjetivo i adverbio, i las lenguas que así se hablan, no son pobres, ni monótonas por eso. Pero no olvidemos que queda por hacer en casi todas las lenguas americanas, si no en todas, la indagación al mismo tiempo filosófica i lingüística de la manera particular de pensar. Aun las más modernas gramáticas no dan más que algunas indicaciones en este sentido. Casi todas ellas ponen los pensamientos en el hecho [lecho] mortífero de Procrústo de la gramática latina" (Barros Arana-Lenz 1893:41, 46).

La relación entre el lenguaje y el pensamiento fue una de sus preocupaciones permanentes (véase 5).

\subsubsection{Algunas características de la estructura gramatical del mapuche}

- No posee ni género gramatical ni declinaciones (como sostuvieron los gramáticos coloniales). 
- En número solo ocurre con propiedad en los pronombres personales (singular, dual y plural).

- Solo conoce sufijos al final de las palabras, los cuales, son, en primer lugar, restos de personales y demostrativos.

- Distingue claramente la función de sustantivo con pronombre posesivo del verbo con sujeto pronominal: en el primer caso se antepone; en el segundo, se pospone (por ejemplo, mi akun, tu llegada; akuimi, llegaste) "particularidad que distingue al araucano del quichua i de la mayor parte de las lenguas americanas".

- Casi todos los sustantivos y adjetivos pueden asumir funciones verbales, agregándoles sufijos demostrativos y personales. De todos los verbos se derivan formas sustantivas.

- Solo existe una palabra con función de preposición, meu o mo, pospuesta, la cual puede expresar todas las relaciones posibles de lugar, tranquilidad: $\tilde{\mathbf{n}}$ s'uká-mo məleimi, "en tu casa estás"; movimiento en dirección a un lugar: mis'uka-mo amoimi, "a tu casa caminas"; movimiento que sale de un lugar: mis'uka-mo kəpaimi, "de tu casa vienes" [...]

El araucano espresa las relaciones de lugar con una precisión incomparable por verbos primitivos, los que todos parecen haber sido monosílabos, i que hoy solo se emplean en composiciones con otras expresiones verbales sustantivas, adjetivas, adverbiales, según su significado castellano: me (ir), pa (venir), tu (ir haciendo), po (llegar para allá), aku (llegar para acá), no (pasar para allá), ru (pasar al lado), etc. (Lenz 1895-1897, Introducción.: XXVI).

\section{La psicología étnica}

De particular interés fue para el Dr. Lenz el tema de la psicología y la lógica y su relación con el lenguaje. En ello influyeron von der Gabelentz, Wundt ${ }^{24}, \mathrm{y}$ probablemente Franz Boas ${ }^{25}$. Para conocer la psicología del lenguaje humano -sostuvo- es indispensable conocer lenguas no indoeuropeas:

Esperar que solo con el estudio de las lenguas europeas pudiéramos llegar a conocer la psicología del lenguaje humano, me parece tan

\footnotetext{
24 "Declaro, pues, que tomo por base las teorías desarrolladas en las numerosas obras del insigne filósofo alemán WILHELM WUNDT, que sin duda alguna, puede ser considerado como uno de los filósofos modernos de mayor autoridad. En mi caso, por otra parte, era el más indicado, porque dejando a un lado mi apreciación personal, es el único autor que ha tratado magistralmente toda la materia científica que tiene interés para nosotros, la psicología individual y étnica y la lógica" (Lenz 1925: 20). El fundamento teórico de su importante obra La oración y sus partes proviene de Wundt. Este investigador utilizó numerosas monografías de lenguas no indoeuropeas
}

${ }^{25}$ El Dr. Lenz mantuvo correspondencia con F. Boas. Véase Velleman 2008. 
razonable como si un naturalista quisiera fundar su fisiología botánica estudiando solo las rosáceas (Lenz 1925: 21). ${ }^{26}$

Los estudiosos del lenguaje humano, con excepción de von der Gabelentz, han olvidado que los idiomas y dialectos indoeuropeos representan un mismo modo de pensar, con variantes solo en los detalles. El conocimiento de otras lenguas pone en evidencia que no hay una manera absoluta de pensar, sino que cada lengua posee un modo particular de unir las ideas ${ }^{27}$. Lamentó que -hasta ese momento- no se hubiera dedicado suficiente estudio a la relación del lenguaje con la psicología general y la lógica; reconoce -eso sí- que ello es muy difícil, pues implica penetrar en el modo de pensar de una lengua completamente extraña. Y, a propósito, nadie habla cabalmente una lengua, en tanto no piense en ella. Al respecto, es importante el estudio de la sintaxis comparada de las lenguas de los diferentes grupos lingüísticos, por ejemplo, indogermánicos, semitas, uraloaltaicos, chinos, considerados desde el punto de vista de la psicología general y la lógica. Von der Gabelentz incluyó en su obra los resultados de sus investigaciones sobre lenguas no indoeuropeas. Debe recomendarse su estudio a filólogos jóvenes e indogermanistas porque se funda en otra base y, por consiguiente, amplía la visión de una manera insospechada (Lenz 1900: 451).

Siempre respecto del tema pensamiento- lenguaje, no aceptó la idea, sostenida por algunos estudiosos, que lo llamados 'salvajes' carecieran de conceptos generales abstractos ${ }^{28}$ :

Cuando por ejemplo, lenguas indígenas son de acuerdo al diccionario pobres en sustantivos abstractos, no se debe esto necesariamente a la estructura lingüística, sino a la falta de oportunidad y necesidad de hacer abstracciones. El mapuche posee una terminación con la que se puede formar un sustantivo abstracto de cada palabra, pero en verdad estas formaciones, de las cuales se alegraban mucho los misioneros de los siglos pasados porque les facilitaban la traducción de los misterios de la religión cristiana, se emplean poco ${ }^{29}$ (Lenz 1901: 584).

\footnotetext{
26 "Die Zoologie darf nicht beim Kaninchen des Physiologen Halt machen, und die Linguistik nicht bei der indogermanischen Sprachfamilie. Beide haben nach Allgemeinheit zu streben, vor verfrühten Verallgemeinerungen sich zu hüten" (Von der Gabelentz 1972: 10).

${ }^{27}$ Cf. en Whorf, 1969: Science and Linguistics.

${ }^{28}$ Según Pickering, citado por Sayce en su obra Introduction to the science of language, el idioma cherokee tendría 13 palabras para lavar determinadas partes del cuerpo o de un objeto, pero ninguna para 'lavar en general' (Lenz 1901:583).

29 "Wenn z.b. indianische sprachen dem wörtebuche nach arm an abstrakten sind, so liegt das durchaus nicht notwendig am sprachbau, sondern an der mangelnden gelegenheit und notwendigkeit zum abstrahiren. Das mapuche hat eine endung, mit der aus jedem worte ein abstraktum gebildet werden kann, aber thatsächlich sind diese bildungen, über die sich die missionäre früherer jahrhunderte sehr freuten, weil sie ihnen die übersetzung der
} 
De igual manera, un ganadero chileno [que no es mapuche] está en condiciones distinguir en una manada de cien cabezas (de animales) doce de ellas según la descripción sencilla que le hace un compañero (y quizá describe a cada una con una palabra), pero

Para nosotros personas civilizadas acaba, desde hace ya mucho tiempo, en veinte cabezas de animales toda posibilidad de diferenciar. Pero nuestros botánicos reconocen cientos de plantas en una hojita del herbario. El lenguaje y la esfera de intereses $\operatorname{coinciden}^{30}$ (Lenz 1901: $585){ }^{31}$

El conocimiento del mapuche es primordial para revelar los pensamientos más profundos, la estructura psíquica de sus usuarios.

\section{La (etno)literatura mapuche}

Constituyó sin duda una novedad afirmar, a fines del siglo XIX, que el pueblo mapuche poseía una literatura propia. Solo había escasas referencias a algún mito (por ejemplo, el del diluvio, en la obra del cronista Diego de Rosales), y a la capacidad oratoria de los mapuches. En los 'parlamentos' que celebraban con los españoles $\left(\mathbf{k o y a g}^{32}\right.$ ) pronunciaban largos discursos, los cuales podían durar horas. Sin embargo, ninguno quedó registrado. En todo caso, no se puede dudar al respecto, pues todavía en el presente, el discurso oral sigue teniendo importancia, mayormente para desempeñar la función de 'cacique' (longko). Este, todavía actualmente en comunidades más conservadoras, debe saber hablar muy bien ante los miembros de las mismas (por ejemplo, cuando tiene lugar el ngillatun, o 'rogativa'). En su discurso De la literatura araucana el Dr. Lenz dejó en claro qué entendía por literatura, para evitar que se la considerara igual a la de otros pueblos más desarrollados:

\footnotetext{
geheimnisse des christenglaubens erleichterten, wenig gebräuchlich".

30 "Für uns kulturmenschen hört bei zwanzig stück rindvieh längst alle unterscheidunsmoglichkeit auf. Aber unsere botaniker erkennen hunderte von pflanzen an einem getrockneten blättchen des herbariums. Sprache und interessensphäre muss sich decken".

31 "The fact that generalized forms of expression are not used does not prove inability to form them, but it merely proves that the mode of life of the people is such that they are not required; that they would, however, develop just as soon as needed [...] This point of view is also corroborated by the study of the numeral systems of primitive languages. As is well known, many languages exist in which the numerals do not exceed two or three. It has been inferred from this that the people speaking these languages are not capable of forming the concepts of higher numbers. I think this interpretation of the existing conditions is quite erroneous $[\ldots]$ In short, there is no proof that the lack of the use of numerals is in any way connected with the inability to form the concepts of higher numbers" (Boas s.f.: 54-55).
}

32 “Coyagh [Koyag] - Parlamento, ò junta grande para parlar”. Coyaghtun [koyagtun], coyaghn [koyagün], hueupin [wewpin] -parlar en esta forma, y hacer dicha junta" (Febrés 1765: 453). 
La literatura araucana no es una literatura de arte en la cual descuellan grandes autores que en sus obras hayan manifestado a sus connacionales cómo se reflejan en el espejo de su intuición poética las fases i situaciones de la vida humana; es una literatura anónima, popular i exclusivamente oral, tal como también en los pueblos civilizados suele existir al lado de las obras de arte (Lenz 1897: 2).

¿Qué lo indujo a interesarse por tal literatura? En primer lugar un motivo etnológico (= antropológico), presente en él desde los inicios de su trabajo científico, como ya hemos señalado:

Averiguar cómo se reflejan en el alma del hombre primitivo el mundo esterior i la vida humana, es averiguar la historia intelectual del jénero humano. El estudio de sus leyendas, de sus ideas mitolójicas y relijiosas, de sus conceptos jurídicos i sociales, nos hace comprender muchas cuestiones que con el esclusivo estudio de las razas civilizadas nunca podríamos resolver. Las investigaciones de los últimos decenios nos han enseñado que a menudo se ha exajerado la distancia que parece haber entre el hombre civilizado i el pueblo natural (Lenz 1897: 12$13)$.

En segundo término, el estudio literario -pensaba- sirve para la recta comprensión de cómo se forman la leyenda, la epopeya, la poesía lírica, "como trabajan la imaginación creadora i la reproductiva [...]" (ibidem). Luego de examinar detenidamente los textos que había obtenido los clasificó según el tipo de producción literaria. Distinguió primero entre el estilo retórico o wewpin (el antiguo koyagtun), de los discursos e invocaciones a las fuerzas naturales, y la creación literaria propiamente tal. Esta última la clasificó a su vez, en poesía cantada (ülkatun) y prosa. Según el argumento, la prosa es epew (cuento) o nütramkan, relación histórica. En los epew distinguió tres clases: 1. el cuento mítico, que contiene alusiones a mitos antiguos y, en general, a hechos sobrenaturales; el cuento de animales, o fábula, en el cual los animales actúan y hablan como humanos, y 3 . el cuento ficticio simple, el cual carece de elementos míticos, "pero que puede contener rasgos que contradicen al realidad" (1897: 1516). En cuanto al nütramkan, que significa 'comunicación' o 'conversación',

i se emplea así para cualquier charla o diálogo sobre asuntos ordinarios de todos los días. Más especialmente se refiere a comunicaciones o narraciones fundadas en hechos importantes de cuya realidad no se duda. Son dignas de apuntarse todas las que se refieren ya sea a la historia o a las costumbres de los indios (Lenz 1897: 34).

Los relatos históricos permiten ver cómo se forma la epopeya nacional:

Pues bien, entre los indios araucanos encontramos todos los elementos primitivos de una grande epopeya histórica. Están dadas todas las 
circunstancias correspondientes. Un pueblo valiente i dotado de viva imajinación poética, empeñado en una guerra a muerte produce héroes como Calvucura, en los cuales se concentran todas las hazañas de innumerables guerreros (Lenz 1897: 36).

Un epew recolectado por el Dr. Lenz ${ }^{33}$ y su versión en pehuenche actual (del Alto Bío-Bío)

\begin{tabular}{|c|c|}
\hline EPEU KANIN EN̦U N̦ÜRÜ & CUENTO DEL JOTE ${ }^{34}$ CON EL ZORRO 35 \\
\hline 1.“Kudeayu, kanin”, pirkei, ņürü. & 1. "Juguemos, jote", dijo el zorro. \\
\hline -Ya, pirkei kanin. & - Bueno, dijo el jote. \\
\hline $\begin{array}{l}\text { Naqai vütta mauwən, t’aņkoñmaleai; } \\
\text { raṇi pun fentenaai; ka taņlin naqtuai. } \\
\text { "Iñei ñi doi puwaqel wüte meu”, } \\
\text { piurkeiņu. }\end{array}$ & $\begin{array}{l}\text { Bajará gran lluvia; granizo habrá; a } \\
\text { media noche se acabará; otra helada } \\
\text { volverá a bajar. “¿De quien el alcanzar a } \\
\text { más en el frío" }{ }^{36} \text {, se dijeron los dos. }\end{array}$ \\
\hline 2. Feimeu "rontaayu" pirkeiņu. & 2. Entonces "rondemos" ${ }^{37}$ dijeron los dos. \\
\hline $\begin{array}{l}\text { Epe raņi pun ramtuņei kanin ñi } \\
\text { tepele. }\end{array}$ & $\begin{array}{l}\text { Casi a media noche fue preguntado el } \\
\text { jote si estaba despierto }\end{array}$ \\
\hline
\end{tabular}

\begin{tabular}{|c|c|}
\hline “T’epelekaimi, kanin?”, pin̨erkei. & “Estás despierto, jote?” le fue dicho \\
\hline -T'epelekan, pirkei & Estoi [todavía] despierto, dijo \\
\hline 3. Ka pəchi allün.meu ramtuņerkei kai & $\begin{array}{l}\text { 3. Otro poco rato después fue } \\
\text { preguntado }\end{array}$ \\
\hline $\begin{array}{l}\text { ņürü: “T’epelekaimi, ņürü?” piņerkei } \\
\text { ņürü. }\end{array}$ & $\begin{array}{l}\text { también el zorro:“¿Estás despierto, } \\
\text { zorro?” le fue dicho al zorro. }\end{array}$ \\
\hline -T'epelelavui wentu? pirkei. & $\begin{array}{l}\text { ¿“No estaría despierto el hombre?”38, } \\
\text { dijo. }\end{array}$ \\
\hline
\end{tabular}

${ }^{33}$ Lenz 1895-1897, Cuentos de animales: 183-184.

${ }^{34}$ El jote, gallinazo, o buitre de cabeza negra (Coragyps atratus) es ave carroñera de la familia Cathartidae. Habita desde Arica hasta Aysén.

${ }^{35}$ El zorro culpeo (Pseudoalopex culpaeus), de la familia Canidae, es un personaje siempre presente en los epew (cuentos) mapuches. Habita en todo el país.

${ }^{36}$ Es decir: ¿quién aguantará más el frío?

${ }^{37}$ Montemos guardia, vigilemos.

${ }^{38}$ Es decir: ¿cómo no habría de estar despierto un hombre como yo? 


\begin{tabular}{|c|c|}
\hline 4. Doi allüpun ramtunerkei kanin ka ñi & 4. Más rato después fue preguntado el \\
\hline $\begin{array}{l}\text { t’epelen.Dewma uwt’ei piam nürü. } \\
\text { “T’epelekaimi, kanin?”piņerkei kanin. } \\
\text { Feimeu eKa dunurkei. Feimeu “Eppe lai } \\
\text { weda kanin”, pirkei ņürü. }\end{array}$ & $\begin{array}{l}\text { jote si también estaba despierto. } \\
\text { Ya tuvo frío, dicen, el zorro. "Estas } \\
\text { despierto jote?" se dijo al jote. } \\
\text { Entonces apenas habló. Entonces “casi } \\
\text { se murió el mal jote”, dijo el zorro. }\end{array}$ \\
\hline $\begin{array}{l}\text { 5. Eppe eppe wün “T'epelekaimi, } \\
\text { nuürü?” piņerkei ņürü. Feimeu epe } \\
\text { chokon lai, piam. Feimeu eKa dunui, } \\
\text { piam. }\end{array}$ & $\begin{array}{l}\text { 5. Casi casi al alba “¿estás despierto, } \\
\text { zorro?” se dijo al zorro. Entonces casi } \\
\text { helado murió, dicen. Entonces apenas } \\
\text { ha bló, dicen }\end{array}$ \\
\hline 6. Ka pəchi allün-mu ramtui, piam, kai. & $\begin{array}{l}\text { 6. Otro poco rato después preguntó, } \\
\text { dicen, también. }\end{array}$ \\
\hline $\begin{array}{l}\text { “T'epelekaimi, nai kanin?”, pirkei } \\
\text { nuürü. Duņurkelai kanin }\end{array}$ & $\begin{array}{l}\text { “Estás despierto, amigo jote?” dijo el } \\
\text { zorro. No habló el jote. }\end{array}$ \\
\hline $\begin{array}{l}\text { 7. Feimeu "lapelai weda kanin", pirkei } \\
\text { nü̈rü; feimeu witarkei kintoavilo } \\
\text { kanin; feimeu wiśt'a-wiśt’atuyauwi, } \\
\text { piam, ņürü. }\end{array}$ & $\begin{array}{l}\text { 7. Entonces “¿no parece que murió el } \\
\text { mal jote?”, dijo el zorro; entonces se } \\
\text { levantó para buscar al jote; entonces } \\
\text { bien levantado caminó, dicen, el zorro. }\end{array}$ \\
\hline $\begin{array}{l}\text { 8. Feimeu“Chumpeimi am, ņüru?” } \\
\text { piņerkei ņürü. }\end{array}$ & $\begin{array}{l}\text { 8. Entonces “¿Cómo estás, zorro?” se } \\
\text { dijo al zorro. }\end{array}$ \\
\hline -WiKi-wiKitupen, pirkei. & -Estoi orinando, dijo. \\
\hline $\begin{array}{l}\text { 9. Liņav naqpachi wün-meu } \\
\text { ramtuṇerkei ņürü ñi t’epele. } \\
\text { "T’epelekan”, pirkei. }\end{array}$ & $\begin{array}{l}\text { 9. Al venir aclarando el alba se le pre- } \\
\text { guntó al zorro si estaba despierto. } \\
\text { "Estoi [todavía] despierto", dijo. }\end{array}$ \\
\hline $\begin{array}{l}\text { 10. Feimeu wün dumdumklewelu- } \\
\text { meu ka ramtuņerkei nürü ñi t’epelen. } \\
\text { "T’epelekaimi, ņürü?”, piņ,erkei. } \\
\text { Duņuwërkelai. }\end{array}$ & $\begin{array}{l}\text { 10. Entonces al alba casi completamente } \\
\text { clara otra vez se preguntó si estaba } \\
\text { despierto.“¿Estás [todavía] despierto, } \\
\text { zorro?” se le dijo. No habló más. }\end{array}$ \\
\hline
\end{tabular}

* Más exactamente: “QQué estás haciendo, zorro?” 


\begin{tabular}{|c|c|}
\hline $\begin{array}{l}\text { 11. Feimeu naqkintupai, piam, kanin. } \\
\text { Feimeu petu lai, piam, nüurü; mankou- } \\
\text { mankoun,ei, piam. }\end{array}$ & $\begin{array}{l}\text { 11. Entonces vino a buscar abajo, } \\
\text { dicen, el jote. Entonces todavía } \\
\text { murió }{ }^{39} \text {, dicen, el zorro; estaba } \\
\text { pataleando, dicen. }\end{array}$ \\
\hline $\begin{array}{l}\text { 12. Feimu kəme wünlu- meu } \\
\text { naqtuñepa- }\end{array}$ & $\begin{array}{l}\text { 12. Entonces al estar bien el alba vino } \\
\text { a }\end{array}$ \\
\hline $\begin{array}{l}\text { rkei ilopatoael; feimeu wüne } \\
\text { nentuñmaņepai, piam, ñi ņe təveichi } \\
\text { ņürü. }\end{array}$ & $\begin{array}{l}\text { bajarse para comer la carne; entonces } \\
\text { pri mero fue a sacarle, dicen, sus ojos } \\
\text { a ese zorro. }\end{array}$ \\
\hline
\end{tabular}

\begin{tabular}{|l|l|}
\hline KOT-TE ${ }^{40}$ ENGU NGÜRÜ & EL JOTE Y EL ZORRO \\
\hline $\begin{array}{l}1 .{ }^{i} \text { Kudeeyu kot-te!”, pirki }{ }^{41} \text { ti ngürü. } \\
\text { “-¡Ya!, pirki ti kot-te. }\end{array}$ & $\begin{array}{l}\text { 1. “iApostemos nosotros dos, jote!”, } \\
\text { dijo, dicen, el zorro. }\end{array}$ \\
\hline $\begin{array}{l}\text { Nagay kiñe püt-ta maw, müley } \\
\text { trangko, }\end{array}$ & $\begin{array}{l}\text { Bajará bien!”, dijo el jote. } \\
\text { se }\end{array}$ \\
\hline $\begin{array}{l}\text { avai rangin travia, ká nagay kiñe püt- } \\
\text { ta trangliñ. - ¿ ¿Ni chi doy topaay utre habrá granizo, } \\
\text { mew?”. }\end{array}$ & $\begin{array}{l}\text { acabará a la media noche, bajará tam- } \\
\text { bién una helada grande. “-¿Quién podrá } \\
\text { (aguantará) más con el frío?”.- }\end{array}$ \\
\hline
\end{tabular}

\begin{tabular}{|l|l|}
\hline $\begin{array}{l}\text { 2. Veymu: "welukentu inarumeaviyu”, } \\
\text { pi-rkingu. Epe rangi travia ramtungi ti } \\
\text { kot-te tayñi tayñi trepelen. }\end{array}$ & $\begin{array}{l}\text { 2. Entonces: "Nosotros dos } \\
\text { vigilaremos”, dijeron. Casi a la media } \\
\text { noche se pre-guntó al jote si estaba } \\
\text { despierto. }\end{array}$ \\
\hline $\begin{array}{l}\text { “Trepelekaymi nay kot-te?”, pingerki. } \\
\text { “Trepelekan”, pirki. }\end{array}$ & $\begin{array}{l}\text { ¿Estás todavía despierto, jote?”, se le } \\
\text { di jo. “Todavía estoy despierto”, dijo. }\end{array}$ \\
\hline & \\
\hline
\end{tabular}

\footnotetext{
${ }^{39}$ Más exactamente: estaba muriendo.

${ }^{40}$ El pehuenche del Alto Bío-Bío ha adoptado el préstamo del español, el cual se usa en vez del nombre mapuche kanin.

${ }^{41}$ Solo traducimos algunas veces el morfema reportativo $\{$-rke-, - rk- $\}$ 'dicen, dicen que', el cual tienen una alta frecuencia en los relatos tradicionales. El narrador deja constancia de que el hecho, el suceso, le ha sido contado, transmitido, por otro(s). Alterna con piam.
} 


\begin{tabular}{|c|c|}
\hline $\begin{array}{l}\text { 3. Ká püchiñma mu ká ramtungi } \\
\text { ti ngürü. “¿Trepelimi nay } \\
\text { ngürü?”,pingerki ti }\end{array}$ & $\begin{array}{l}\text { 3. Al rato, otra vez se le preguntó al } \\
\text { zorro. “¿Estás despierto, zorro?”, se le }\end{array}$ \\
\hline ngürü. & dijo al zorro. \\
\hline $\begin{array}{l}\text { “Chumtrepelelay tati wentru inche } \\
\text { re-ke?”, pirki. }\end{array}$ & $\begin{array}{l}\text { ¿Cómo no habría de estar despierto } \\
\text { un hombre como yo?”, dijo. }\end{array}$ \\
\hline $\begin{array}{l}\text { 4. Ká püchiñma mu ká ramtungerki } \\
\text { kot-te tayñi trepelevel. Chayno utrerki } \\
\text { ti ngü-rü }\end{array}$ & $\begin{array}{l}\text { 4. Al rato, otra vez se le preguntó al } \\
\text { jote si estaba despierto. Ya tenía frío el } \\
\text { zorro. }\end{array}$ \\
\hline $\begin{array}{l}\text { “Trepelimi nay kot-te?”, ramturngerki } \\
\mathrm{ti}\end{array}$ & “¿Estás despierto, pues, jote?”, se le \\
\hline kot-te. Veymu weya dungurki. & preguntó al jote. Entonces habló mal. \\
\hline “EEe lay weda kot-te!”, pirki ti ngürü. & $\begin{array}{l}\text { “Casi se murió el jote malvado!”, dijo } \\
\text { el zorro. }\end{array}$ \\
\hline $\begin{array}{l}\text { 5. Epe livlu wün vey: “¿Trepelimi } \\
\text { ngürü?”, pingerki ti ngürü. Veymu } \\
\text { epe utrenarkewüy, pingi. Veymu weya } \\
\text { ulparki iñ dungun. }\end{array}$ & $\begin{array}{l}\text { 5. “Casi amaneciendo: “¿Estás } \\
\text { despierto zorro?”, se le dijo al zorro. . } \\
\text { Entonces ca-si se heló, dicen. Entonces } \\
\text { le salió mal el habla }{ }^{42} \text {. }\end{array}$ \\
\hline $\begin{array}{l}\text { 6. Ká püchiñma mu ramturki: “¿Trepe- } \\
\text { limi nay kot-te?”, pirki ti ngürü. } \\
\text { Veymu }\end{array}$ & $\begin{array}{l}\text { 6. Al rato, preguntó: “¿Estás despierto, } \\
\text { jote?”, dijo el zorro. Entonces, dicen }\end{array}$ \\
\hline $\begin{array}{l}\text { dungurkelay ti kot-te. } \\
\text { “iLalu tati weda kot-te chukuviñn!”, } \\
\text { pirki ti ngürü. }\end{array}$ & $\begin{array}{l}\text { que no habló el jote. } \\
\text { “-¡Creo que está muerto el jote malva- } \\
\text { do!”, dijo el zorro. }\end{array}$ \\
\hline $\begin{array}{l}\text { 7. Veymu utrarki ti kot-te tayñi kintu- } \\
\text { mevel. Veymu utrautraturki ti ngürü. }\end{array}$ & $\begin{array}{l}\text { 7. Entonces se paró el jote para ir a } \\
\text { verlo. Entonces se paró bien el zorro. }\end{array}$ \\
\hline
\end{tabular}

\begin{tabular}{|l|l|}
\hline $\begin{array}{l}\text { 8. Veymu: “-¿Chumpimi nay, ngürü?”, pi } \\
\text { ngerki. } \\
\text { - “Willitupen”, pirki ti ngürü. }\end{array}$ & $\begin{array}{l}\text { 8. “-¿Qué estás haciendo, pues, zorro?”, } \\
\text { se le dijo. } \\
\text { “-Estoy meando”, dijo el zorro. }\end{array}$ \\
\hline & $\begin{array}{l}\text { 9. Casi al aclarar la aurora se le } \\
\text { preguntó }\end{array}$ \\
\hline 9. Epe livlu wün ramtungerki ti ngürü
\end{tabular}

${ }^{42}$ Apenas pudo hablar. 


\begin{tabular}{|l|l|}
\hline tayñi trepelen. & al zorro si estaba despierto. \\
\hline -“Trepelekan”, pirki. & “- Estoy todavía despierto”, dijo. \\
\hline $\begin{array}{l}\text { 10. Veymew dumdumkülewelu mu ká } \\
\text { ramtungerki ti ngürü tayñi trepelekan: } \\
\text { “-¿Trepelimi nay, ngürü?”, pingerki. }\end{array}$ & $\begin{array}{l}\text { 10. Cuando ya no estaba oscuro, } \\
\text { de nue-vo se le preguntó al zorro } \\
\text { si todavía estaba despierto: ¿Estás } \\
\text { despierto, pues, zorro?”, se le dijo. }\end{array}$ \\
\hline Chayno dunguwerkelay. & Dicen que ya no habló. \\
\hline $\begin{array}{l}\text { 11. Veymu nagparki kot-te tayñi } \\
\text { kintupaial. Metu larkelay ti ngürü. } \\
\text { Mangkowmangkowngerki. }\end{array}$ & $\begin{array}{l}\text { 11. Entonces bajó el jote a mirar. Toda- } \\
\text { vía no había muerto el zorro. Estaba } \\
\text { pa-taleando. }\end{array}$ \\
\hline $\begin{array}{l}\text { 12. Lingavnaglu wün nagparki kot- } \\
\text { te tayñi ilotungeal (ngürü). Veymu } \\
\text { wema nentuñmangerki ñi nge tati ngürü. }\end{array}$ & $\begin{array}{l}\text { 12. Cuando amaneció dicen que bajó } \\
\text { para comerse (al zorro). Entonces, pri- } \\
\text { meró los ojos al zorro. }\end{array}$ \\
\hline
\end{tabular}

\section{Creencias de los mapuches}

Como ya señalamos, el Dr. Lenz no solamente se interesó por la lengua vernácula desde un punto de vista estrictamente lingüístico, sino también por los aspectos etnológicos (=antropológicos) asociados a ella. Lamentó la falta de preocupación y de interés mostrados tradicionalmente por esos aspectos y -cuando ocurrió- los prejuicios con que fueron tratados. De ello fueron responsables los cronistas y misioneros. Al respecto, por ejemplo, los primeros afirmaron que los indígenas no poseían divinidades. Sin embargo, los textos recolectados por él mostraban lo contrario. Si bien es cierto que no poseían un culto organizado, con templos, sí ha existido uno dedicado a los antepasados, a los genios de ciertos lugares (por ejemplo, en algunos pasos cordilleranos, en los cuales los viajeros dejaban ofrendas) para propiciarlos ${ }^{43}$.Tocante al actual Ngünechen -'el que gobierna a la gente'-, Chao Dios, se trata del dios cristiano indianizado "por cuya doctrina los araucanos no han mostrado nunca mucha comprensión $^{44 ”}$ (1895: 8). En todo caso, en relación con las creencias, faltaba

\footnotetext{
${ }^{43}$ Véase La piedra santa de Retricura (en Estudios Araucanos: 423 y ss.).

${ }^{44}$ [...] Ich vermute, dass der "Herrscher des Menschen (Ngünechén)" aus Kalvuns Märchen, ebenso wie Kintuprais "Gottvater" (Chao Dios) der etwas indianisierte Christengott ist, für dessen Lehre übrigens die Araukaner niemals viel Verständnis gezeigt haben" (Lenz 1896: 8). Ngünechen ocurre en varios relatos de los Estudios Araucanos (por ejemplo, en Cuento de un pajarito, llamado caminante (pág. 219), Cuento del tigre y el zorro (pág. 219), El viejo Latrapai (pág. 227), La hija del cherruve (pág. 259), etc.
} 
aún mucho por conocer, por ejemplo acerca del ngillatun ${ }^{45}$, las prácticas de sanación de los machi (curandero/a), los mitos antiguos, etc. También faltaba por estudiar las ceremonias sociales, como aquellas que tenían lugar al nacer un niño, al ponerle nombre, al entrar en la edad adulta, como también las ceremonias funerarias. Le interesaba conocer, además, los procedimientos relacionados con el arte, con la construcción de casas (rukan, rukatun), la confección de tejidos, la alfarería "antes de que sean barridos por los progresos que la industria europea hace entre ellos" (1897: 14). Había, pues, un vasto campo por explorar. Y al conocimiento de su cultura podían contribuir los mismos indígenas, aportando valiosos datos, cuando "hacen las descripciones exactas de todas esas cosas en su propio idioma, como Calvún ha descrito la trilla con los pies, la veneración de la Piedra Santa de Retricura i otras cosas" (ibidem).

\section{Su simpatía y preocupación por la 'gente de la tierra'}

A diferencia de muchos chilenos de entonces - y también de algunos del presente- que despreciaban a los mapuches, el juicio del Dr. Lenz sobre ellos fue siempre positivo.

Conozco -escribió- pero no creo justificada la opinión que tienen tantos chilenos, de que no valgan para nada los indios actuales. Creo que hai muchos entre ellos que pudieran llegar a ser miembros útiles del pueblo chileno, si se los tratara de una manera conveniente, si se supiera asimilarlos" (Lenz 1895-1897, Introducción: XIV).

Después de conocerlos, pensaba que los mapuches poseían una inteligencia más viva que otros pueblos americanos, la cual les permitió adaptarse a las condiciones de la conquista. "Por esta y otras razones creo que los araucanos son más capaces de civilizarse que la mayor parte de los indios americanos" (ibidem). En el sur observó con cuanta facilidad un indígena aprendió a manejar maquinaria agrícola. De ellos provenía -sostuvo- una fuerza superior que caracteriza a la nación chilena. Como es sabido, opusieron una tenaz resistencia ante los españoles.

Dotados de una intelijencia más viva que la de muchos otros indíjenas, i con la facultad de adaptar su vida i costumbres a nuevas necesidades, aprendieron de sus enemigos el uso del caballo, reformaron su armamento i su táctica i así llegaron más de una vez a vencer a los conquistadores del Nuevo Mundo. Por esta i por otras razones creo yo que los araucanos son más capaces de civilizarse que la mayor parte de los indios americanos" (Lenz 1895-1897, Introducción: XIV).

\footnotetext{
${ }^{45}$ Ngillatún 'pedir otra vez': ceremonia religiosa tradicional, en la cual los miembros de la comunidad piden a la divinidad mapuche ngünechen ('el que dirige o gobierna a la gente') que vele por sus sembrados y animales domésticos, mande lluvia o buen tiempo -según sea necesario- y les proporcione bienestar, tanto físico como espiritual.
} 
En su discurso De la literatura araucana expresó:

Si me permito ocupar por lo menos unos cuantos minutos la atención de esta distinguida reunión, lo hago en la creencia de que todo lo que se relaciona con los indios araucanos tiene el derecho de reclamar la atención de los chilenos instruidos no menos que todo lo que se relaciona con los conquistadores españoles; si estos son los antepasados de las clases gobernantes, aquellos han dado la base sobre la cual se ha formado la masa del bajo pueblo de la República” (Lenz 1897: 3).

Y agregó: “¿Por qué no habría un auditorio que oyera con agrado el resultado de nuevos estudios sobre nuestros indios?" (subrayado nuestro) (1897: 4). El chileno que surgió de la mezcla de conquistadores e indígenas debe, por su parte, muchos conocimientos

al indio que puso nombre a tantas plantas i a tantos animales, que enseñó a gozar de la naturaleza del país para la manutención física de los numerosos guisos de la cocina i para la conservación de la salud con los innumerables remedios. Quizás con sorpresa oirán que aun industrias como la del telar no las debe el chileno a España sino al indio" (Lenz 1905-1910: 41).

¿Qué papel debe asumir el gobierno chileno respecto de ellos? Debe preocuparse de civilizarlos y educarlos, pero empleando su lengua.

Los profesores de idioma y de historia, sobre todo los que viven todavía donde existen indios, que hablan su lengua, son las personas más indicadas para continuar los estudios araucanistas, y colaborar así en la tarea de la civilización de los indios, para salvar en beneficio de la nación chilena esas inapreciables fuerzas físicas e intelectuales del indio. Así como es obligación del gobierno establecer escuelas para enseñar el castellano a los indígenas (i los profesores, naturalmente, deben hablar al menos medianamente la lengua de los educandos), así también es necesario que los empleados públicos (judiciales, administrativos, agrimensores, etc.), encargados de la radicación definitiva de los indígenas, se busquen de preferencia entre personas que conocen el idioma mapuche" (Lenz 1917: 135-136).

¡Difícilmente habría encontrado la gente mapuche, en un momento muy difícil de su existencia como pueblo, un mejor defensor!

En una cosa, afortunadamente, se equivocó, a saber, que el pueblo mapuche, junto con su lengua, desaparecería, dada su situación a fines del siglo XIX ${ }^{46}$.

Hace solo unos tres decenios desde que han abandonado casi por entero la resistencia bélica; hoy rechazados cada vez más lejos por los colonos agricultores [que ocuparon sus tierras], están condenados a extinguirse. Dentro de cincuenta años [en 1943] el último descendiente

\footnotetext{
${ }^{46}$ Debido a la llamada "pacificación de la Araucanía" (1861-1883), la cual, en verdad, no fue pacífica.
} 
de esta valiente estirpe en la ladera occidental de los Andes habrá abandonado su traje y su lengua nacionales" (Lenz 1940:257. Escrito originalmente en 1893).

\section{Conclusiones}

1. El Dr. Rodolfo Lenz dio inició en Chile a la investigación científica del español chileno y del mapuche, lo cual hasta fines del siglo XIX nadie había llevado a cabo.

2. Inició la investigación etnolingüística y dialectológica del mapuche moderno. Para conocer la lengua hablada viajó a la Araucanía, obteniendo muestras de boca de hablantes actuales, las cuales transcribió con gran exactitud, dada su experticia en fonética. Intuyó la noción de fonema. Aplicó una metodología inédita mediante entrevistas en el terreno. Como solo podía realizar trabajo de campo en las vacaciones, su permanencias in situ fueron breves, pero productivas.

3. Sus publicaciones sobre el mapuche -en primer lugar los Estudios Araucanos- constituyen un paso obligado para quienes pretenden estudiar científicamente dicha lengua y su cultura. Su interés no solo se centró en las estructuras lingüísticas, sino también en los aspectos de la cultura asociados a la lengua. Para ello recolectó textos en los cuales se manifestaba, como cuentos (epew), relatos autobiográficos, históricos y míticos (nütramkan), cantos y poesías (ülkatun ${ }^{47}$ ). A la vez le interesó investigar la manera de pensar y la Weltanschauung de los indígenas.

4. El Dr. Lenz mostró permanentemente gran simpatía y respeto por la "gente de la tierra", por los cuales abogó para que se los valorara y no fueran objeto de discriminación, deseando para ellos un mejor trato -en una época difícil para el pueblo mapuche- y pudieran mediante la educación, integrarse al país.

5. El Dr. Lenz ha ejercido influencia sobre estudiosos coetáneos y posteriores de la lengua mapuche, entre los cuales figuran misioneros capuchinos e investigadores chilenos y extranjeros.

6. El Dr. Lenz fue un profesor que vino desde muy lejos a enseñar a los chilenos a valorar a sus indígenas -los que han contribuido a formar una nacionalidad mestiza-, su lengua y su cultura. No regresó nunca a su país natal, Alemania, y sus restos mortales descansan en Santiago de Chile.

\section{Bibliografía}

Alonso, Amado y Lida, Raimundo. 1940. El español en Chile. Trabajos de Rodolfo Lenz, Andrés Bello y Rodolfo Oroz. Traducción, notas y apéndices de Amado Alonso y Raimundo Lida. Biblioteca de Dialectología Hispanoamericana VI.

${ }^{47}$ También ül, ülkantun. 
Buenos Aires: Facultad de Filosofía y Letras de la Facultad de Filosofía y Letras de la Universidad de Buenos Aires, Instituto de Filología.

Augusta, Fray Félix José de. 1903. Gramática Araucana. Valdivia: Imprenta Central, J. Lampert.

Augusta, Fray Félix José de. 1910. Lecturas Araucanas (Narraciones, costumbres, cuentos, canciones, etc.) Con la cooperación de Fray Sigifredo de Fraunhaeusl, misioneros apostólicos de la Provincia de Baviera. Valdivia: Imprenta de la Prefectura Apostólica.

Barros Arana, Diego y Lenz, Rodolfo. 1893. La lingüística americana. Su historia i estado actual. (Publicado en los "Anales de la Universidad"). Santiago de Chile: Imprenta Cervantes.

Boas, Franz. s.f. Introduction to the Handbook of American Indian Languages. Washington: Georgetown University Press.

Escudero, Alfonso M.. 1963. Rodolfo Lenz. Bogotá: Instituto Caro y Cuervo. Tirada aparte de Thesaurus, Boletín del Instituto Caro y Cuervo. Tomo XVIII, 1963. Incluye bibliografía del Dr. Lenz, $40 \mathrm{pp}$.

Febrés, Andrés. 1765. Arte de la lengua general del Reyno de Chile, con un diálogo Chileno-Hispano muy curioso, a que se añade la Doctrina Christiana, esto es, Rezo, Catecismo, Coplas, Confesionario y Pláticas, lo más en lengua Chilena y Castellana. Y por fin un Vocabulario Hispano-Chileno, y un Calepino Chileno-Hispano más copioso. Con Licencia: en Lima, en la calle de la Encarnación. Año de 1765.

Guevara, Tomás. 1911. Folklore araucano. Refranes, cuentos, cantos, procedimientos industriales, costumbres prehispanas. Santiago: Imprenta Cervantes.

Lenz, Rodolfo. 1887. “Zur Physiologie der Palatalen”. Gütersloh: C. Bertersmann. Tirada aparte de Zeitschrift für Vergleichende Sprachforschung auf dem Gebiete der indogermanischen Sprachen. 62 páginas más currículo (Lebenslauf) y resumen de Tesis.

Lenz, Rodolfo. 1895-1897. Estudios Araucanos. Materiales para el estudio de la lengua, la literatura i las costumbres de los indios mapuches o araucanos. Diálogos en cuatro dialectos, cuentos populares, narraciones históricas, i cantos de los indios de Chile en lengua mapuche, con traducción literal castellana. Santiago: Imprenta Cervantes.

Lenz, Rodolfo. 1895-1898. "Der Ausbruch des Vulkans Calbuco nach der Beschreibung eines Indianers von Osorno". Separata de Verhandlungen des Deutschen Wissenschaftichen Vereins zu Santiago de Chile. Tomo III: 133-139. Valparaíso: Imprenta del Universo de Guillermo Helfmann.

Lenz, Rodolfo. 1896. Araukanische Märchen und Erzählungen, mitgeteilt von Segundo Jara (Kalvun). Gesammelt und übersetzt von Dr. Rudolf Lenz. Valparaíso: Imprenta del Universo de Guillermo Helfmann.

Lenz, Rodolfo. 1897. "De la literatura araucana. Discurso leído en la sesión pública de la Facultad de Filosofía i Humanidades de la Universidad de Chile el $1^{\circ}$ de octubre de 1897”. Separata de la Revista del Sur, año I N ${ }^{\circ}$ 7: 1-44. Chillán: Imprenta y Encuadernación de la Librería Americana de Carlos F. López. 
Lenz, Rodolfo. 1900-1901. "Über Ursprung und Entwicklung der Sprache mit besonder Berücksichtigung von Jespersens Progress in Language". En: Die neueren Sprachen. Vol. VIII (1900), Heft 8: 449-472, Vol. VIII (1901), núm. 9: 513-534, núm. 10: 577-589.

Lenz, Rodolfo. 1905-1910. Diccionario etimolójico de las voces chilenas derivadas de lenguas indijenas americanas. Santiago: Imprenta Cervantes.

Lenz, Rodolfo. 1912. "Los elementos indios del castellano de Chile". Extracto del XVII Congreso Internacional de Americanistas, p. 292 y siguientes. Buenos Aires: Imprenta Coni Hermanos.

Lenz, Rodolfo. 1917. "Un diccionario araucano”. Revista Chilena, Tomo II: 130-136.

Lenz, Rodolfo. 1919. "Sobre el estudio de idiomas". Carta al señor don Julio Molina Saavedra (y respuesta de Julio Saavedra). Santiago: Sociedad Imprenta i Litografía Barcelona.

Lenz, Rodolfo. 1920. La enseñanza del castellano i la reforma de la gramática. Memoria presentada al Honorable Consejo de Instrucción Pública por el Dr. Rodolfo Lenz. Profesor del Instituto Pedagojico (Universidad de Chile). Santiago de Chile: Soc. Imprenta i Litografía Universo.

Lenz, Rodolfo. 1924. "Estudio sobre los indios de Chile". Extracto de "Publicaciones del Museo de Etnolojía y Antropolojía de Chile”. Tomo I, núms. 1 y 2: 147-160. Santiago: Imprenta Cervantes.

Lenz, Rodolfo. 1925. La oración y sus partes. Estudios de gramática general y castellana. Segunda edición. Madrid: Publicaciones de la Revista de Filología Española.

Lenz, Rodolfo. 1930. Prólogo a Vida y costumbres de los indígenas araucanos en la segunda mitad del siglo XIX, del P. Ernesto Wilhelm de Moesbach: 6 - 7.

Lenz, Rodolfo. 1940. "Para el conocimiento del español de América [1893]". En: Alonso, Amado y Raimundo Lida. El español en Chile: pp. 209-258.

Manquilef, Manuel. 1911. "Comentarios del pueblo araucano I (la faz social)". AUCh, tomo 128 (1911): 3-60.

Manquilef, Manuel. 1914. "Comentarios del pueblo araucano II. La jimnasia nacional (juegos, ejercicios guerreros i deportivos i bailes)". AUCh, tomo 134 (1914): 239256.

Pino Saavedra, Yolando. 1987. Cuentos mapuches de Chile. Santiago de Chile: Ediciones de la Universidad de Chile.

Rovillo de Saunière, Sperata. 1975. Cuentos populares araucanos y chilenos. Recogidos de la tradición oral. Biblioteca Popular Nascimento. Santiago de Chile: Editorial Nascimento.

Sánchez, Gilberto. 1992. "La contribución del Dr. Rodolfo Lenz al conocimiento de la lengua y cultura mapuches”. BFUCh XXXIII (1992): 273-299.

Suarez, G. 1959. “The Phonemes of an Araucanian Dialect”. IJAL 25.3: 177-181.

Velleman, Barry. 2008. "La imagen y los ecos del lingüista profesional: la 
correspondencia de Rodolfo Lenz. The image and the echoes of the professional lingüist: the correspondence of Rodolfo Lenz". RLA Revista de Lingüística Teórica y Aplicada. Concepción (Chile), 46 (1), Primer Semestre 2008: 11-28.

Vicuña, Claudio. 1938. "El Dr. Rodolfo Lenz (semblanza del maestro)”. Anales de la Facultad de Filosofía y Educación. Sección Filología. Tomo II, cuaderno I (19371938). Homenaje a la memoria del Dr. Rodolfo Lenz: 7-10.

Von der Gabelentz, Georg [1891]. 1972. Die Sprachwissenschaft, ihre Aufgaben, Methoden und bisherigen Ergebnisse. Con un estudio de Eugenio Coseriu, reeditado por Gunter Narr y Uwe Petersen. $2^{\mathrm{a}}$ edición. Tubinga: Editora TBL.

Whorf, Benjamin L. 1969. Language, Thought and Reality. Selected Writings of Benjamin Lee Whorf. Cambridge, Mass.: The MIT Press.

Wilhelm de Moesbach, Ernesto. 1930. Vida y costumbres de los indigenas araucanos en la segunda mitad del siglo XIX. Santiago de Chile: Imprenta Cervantes.

Wundt, Wilhelm. 1904. Völkerpsychologie. Eine Untersuchung der Entwicklungsgesetze von Sprache, Mythos und Sitte. Primer volumen: Die Sprache. Segunda edición corregida y aumentada. Leipzig: Editora de Wilhelm Engelmann.

Data recebimento: 05/11/2014.

Data aceite: $20 / 11 / 2014$. 
RODOLFO LENZ (1927)

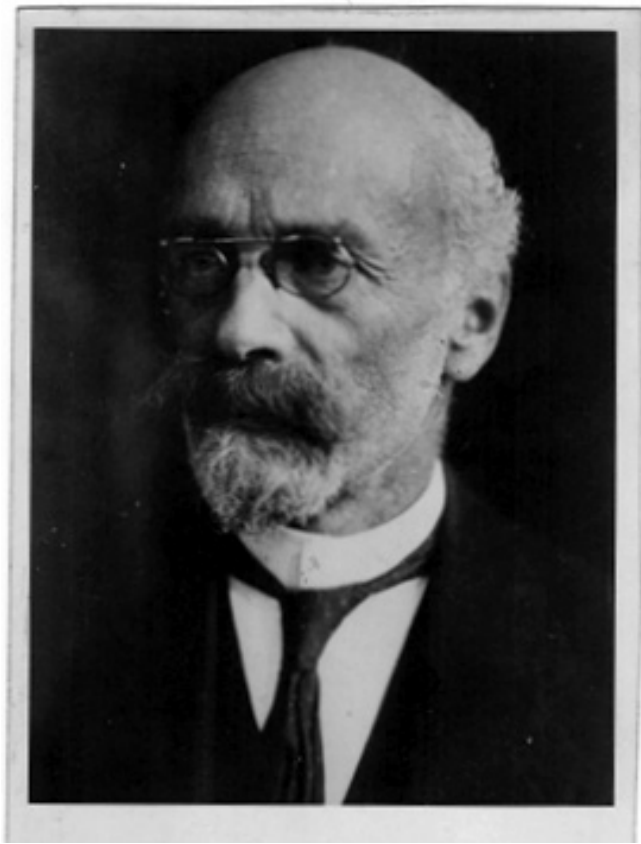

DOCTOR LENZ Y OTRAS PERSONAS (8 de agosto de 1925, Cerro San Cristóbal

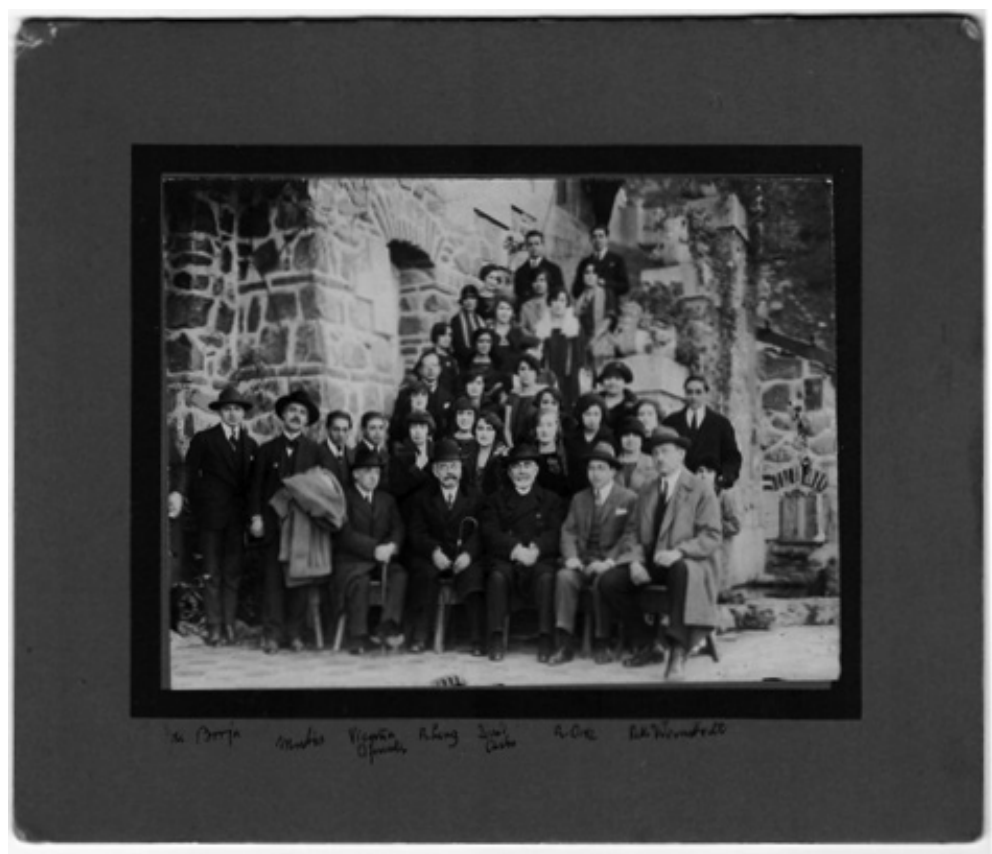

Volume 6, Número 2, Dezembro de 2014533 


\section{SEGUNDO JARA (Calbún)}

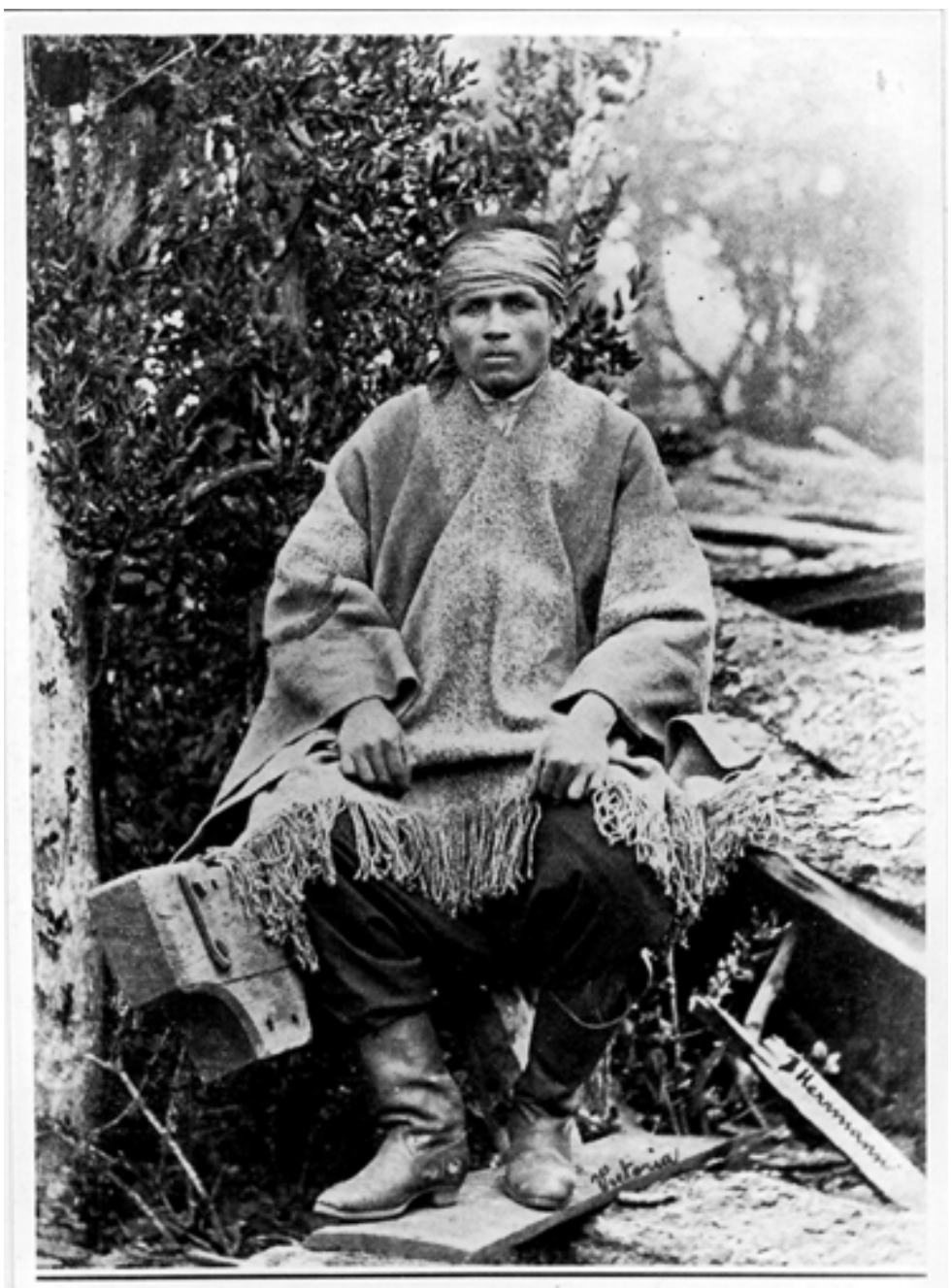

Segundo Jara Kalbum 